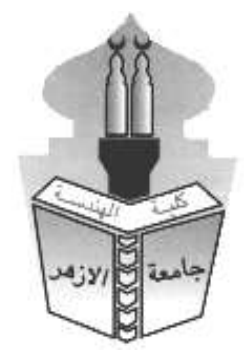

Vol. 16 , No,61, October $2021,1489-1502$

\title{
ROLE OF EGYPTIAN (HAMLETS) VILLAGES SUBSIDIARIES "EZAB,KOFOR,NOGOA" IN FORMULATION THE EGYPTIAN RURAL PHYSICAL PATTERN
}

\author{
Kamal Khalaf Ismail, Ahmed Nagib Elkady, Shaban Abu Khatwa \\ Urban Planning Eng Department, Faculty of Engineering, Al-Azhar University, Cairo, \\ Egypt \\ Mostafa Helmy Mohamed \\ *Corresponding Author's E-mail: eng azhar2003@yahoo.com
}

Received : 21 August 2021 Accepted : 10 September 2021

\begin{abstract}
:
The concept of the rural physical pattern is linked to a number of planning levels, starting from the national level to the local level. Despite the importance of each of the physical patterns (rural and urban), most of the research tended to focus on the urban pattern to focus on cities, their growth and the development of planning theories. The aspects of rural urbanization began to receive a great deal of attention, especially from the geographical point of view at the beginning of the twentieth century.

The satellites of the Egyptian villages (ezab, kofor, and nogoa) are the basic nucleus of the Egyptian village and the origin of the formation of the Egyptian countryside. This research reviews a number of features of these satellites in terms of defining them, their beginnings, the reasons for their emergence, their historical development, the organizing framework for them, their legal status and some of their social and urban characteristics in order to know the size and extent of the impact of these satellites in forming the Egyptian rural population and the impact of their distribution on the physical pattern, especially with their large number and in The diversity of its forms and nature.

The research concluded a number of results, the most important of which is the link between the subsidiaries of the villages and the agricultural land tenure systems and the presence of a strong reflection of the administrative and legislative systems on the size of the villages' subsidiaries, and the importance of developing multiple alternatives for rural development with good urban management, especially with regard to controlling urban growth and coordination between the relevant authorities to ensure optimal exploitation for the efforts and integration between them.
\end{abstract}

KEYWORDS:(Hamlets “ villages subsidiaries” - Ezab,Kofor,Nogoa - Physical pattern Egyptian rural pattern) 


\section{دور توابع القرى المصرية "العزب والكفور والنجوع" فى تثكيل النسق العمرانى الريفى المصرى التيا كمال خلف اسماعيل، أحمد نجيب القاضى، شعبان أبو خطوة \\ قسم التخطيط العمرانى، كلية الهندسة، جامعة الأزهر، القاهرة، مصر \\ مصطقى حلمى محمد}

eng_azhar2003@yahoo.com : البريد الاكترونى للباحث الرئيسى *

الملخص:

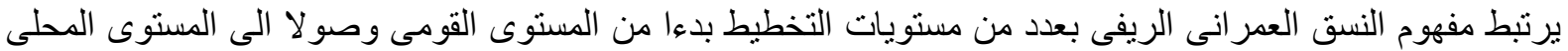

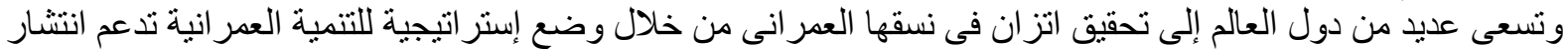

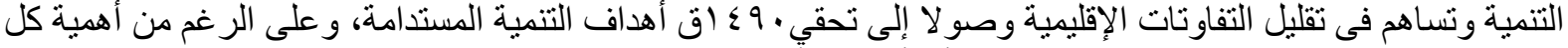

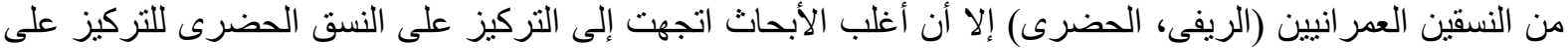

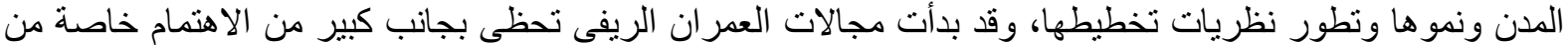
الناحية الجغر افية في بداية القرن العشرين.

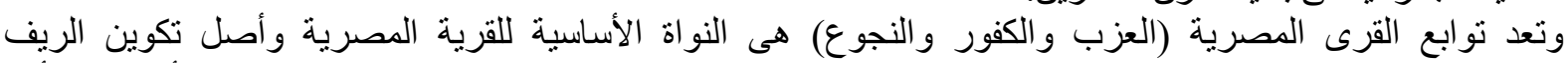

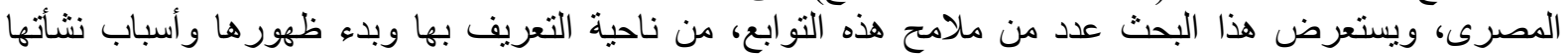

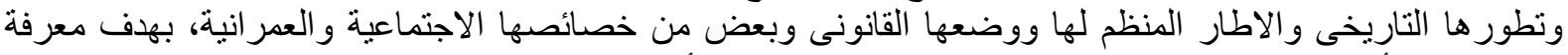

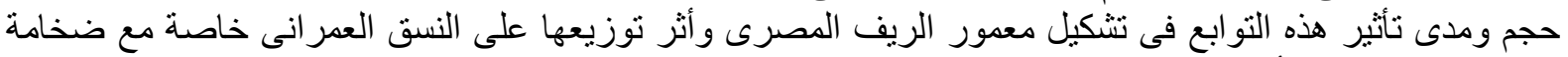

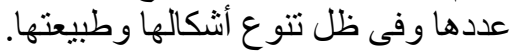

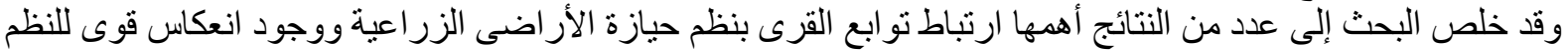

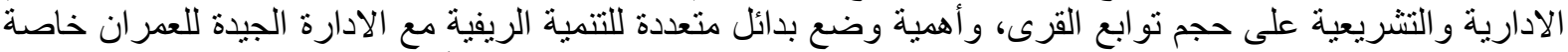

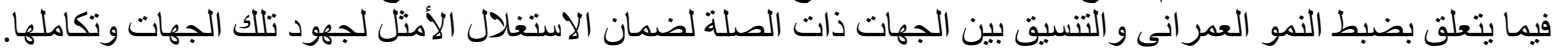

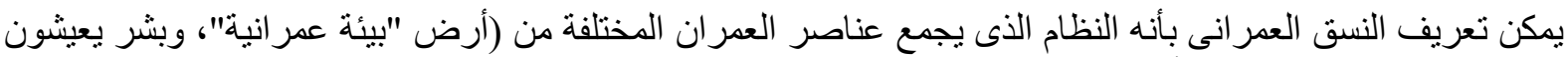

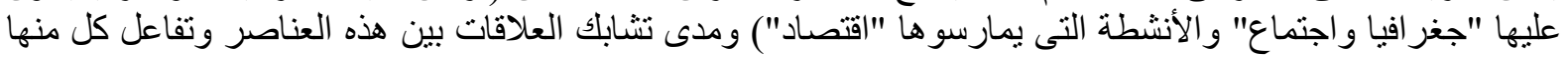

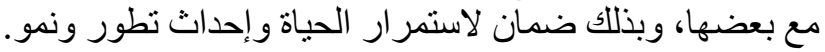

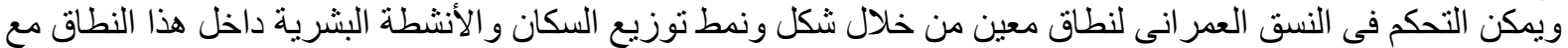

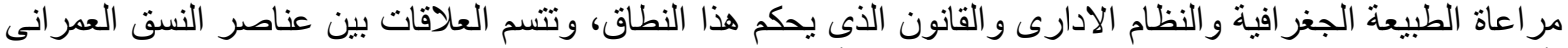

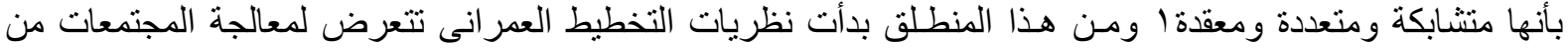

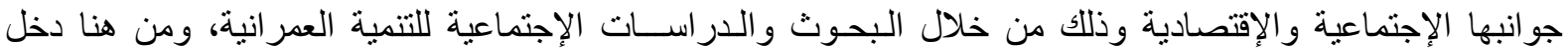

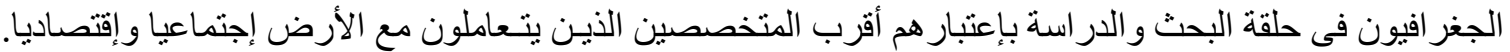

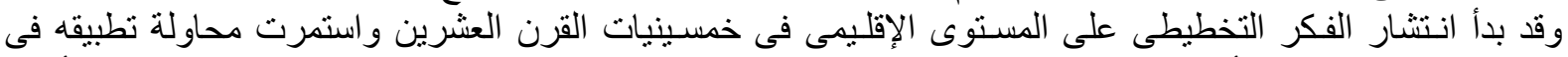

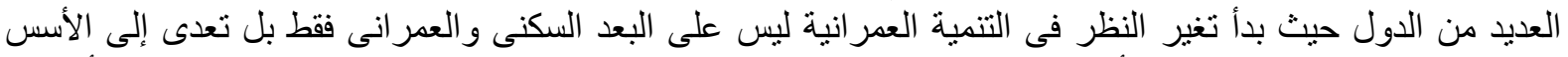

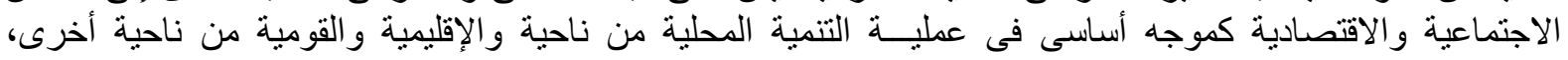

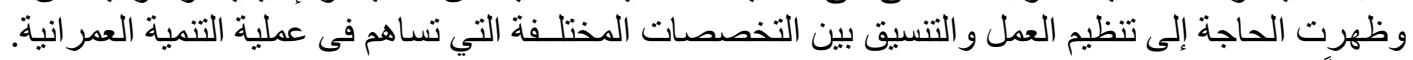

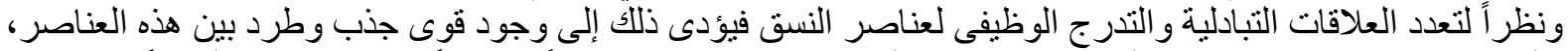

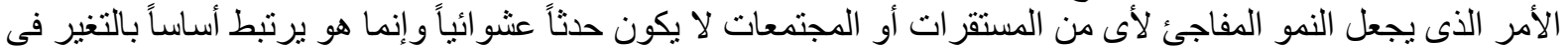

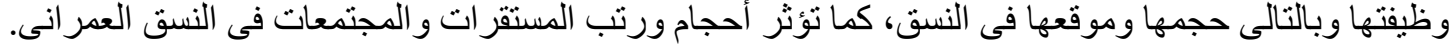

الكلمات المفتاحية: توابع القرى ـ العزب والكفور والنجوع - النسق العمرانى ـ النسق الريفى المصرى 


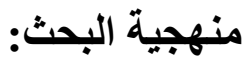

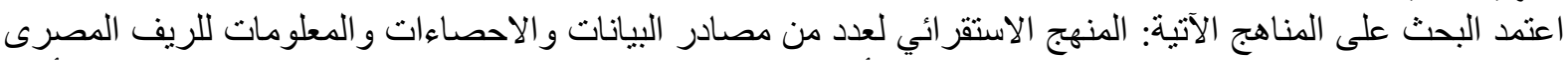

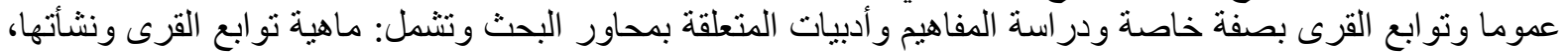

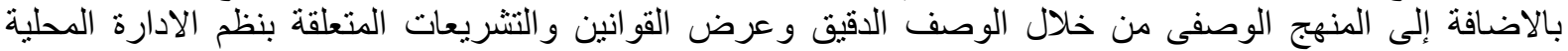
و العمر ان ثم عرض تفصيلى لتو ابع القرى بكل محافظة للوصول الى الى المنهج التحليلى للحصول على نتائج منطقية بهدف التهات وضع وتصور للمقترحات التى تحقق أهداف البحث.

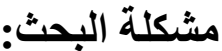

ترتبط تو ابع القرى الكصرية أو ما يعرف بالعزب و الكفور و النجوع بالريف المصرى والذي يعتد غالبية سكانه على نشاط

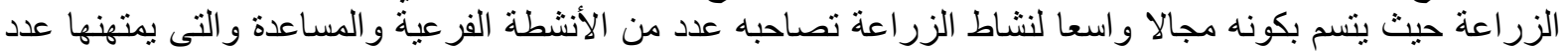

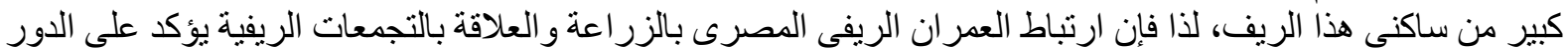

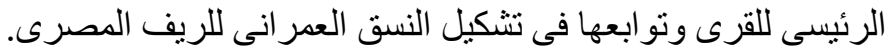

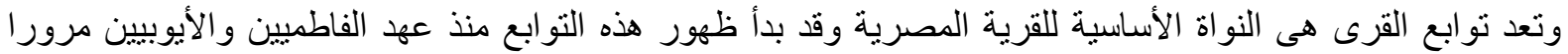

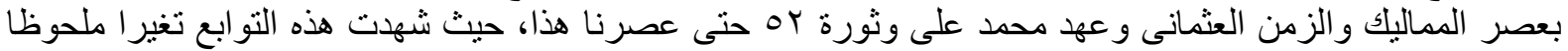

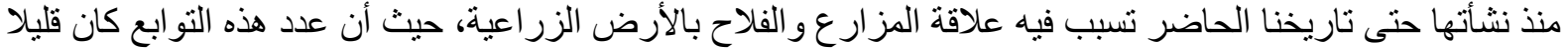

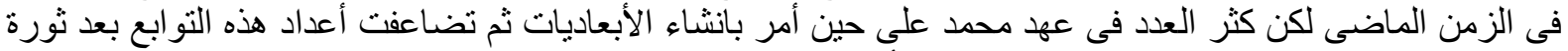

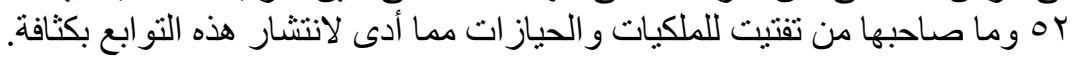

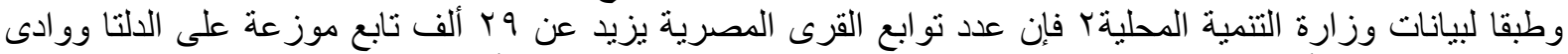

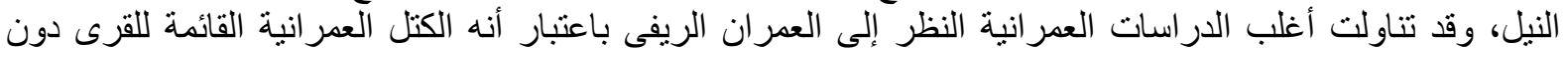
مر اعاة لتو ابع القرى و التى تمثل عمر ان مكمل للريف المصرى كما تلعب دورا هاما فى تثكيله.

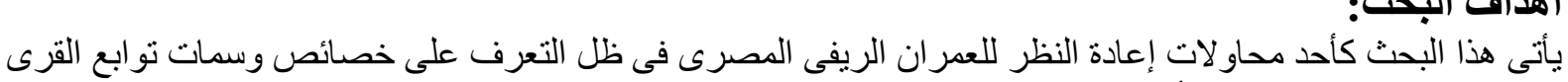

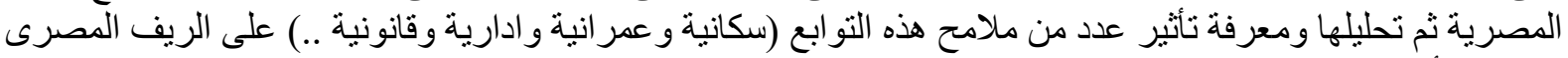

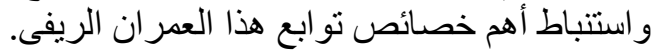

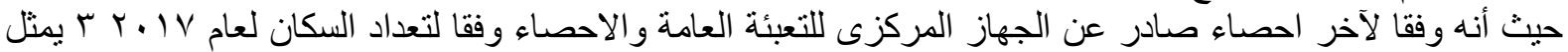

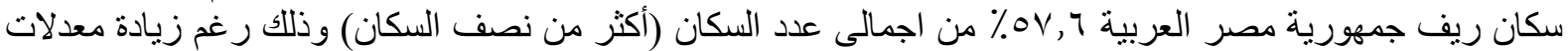
التحضر عالميا.

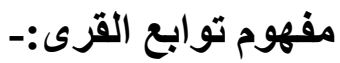

يقصد بتو ابع القرية التجمعات العمر انية الصغيرة التى تقع ضمن زمام القرية وترتبط بها من حيث الزراعة التهات والرىى، حيث

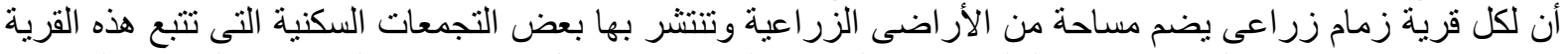

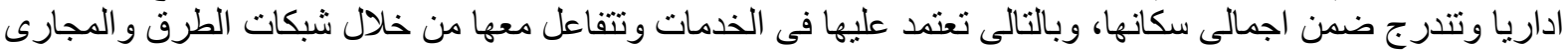

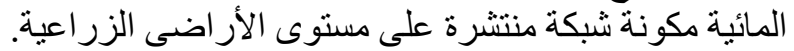

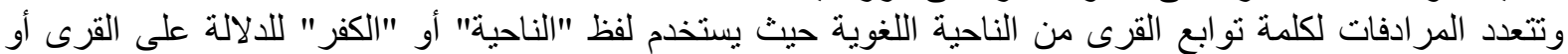

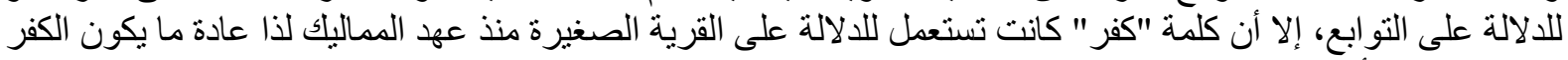

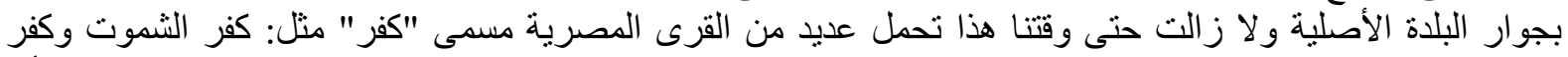

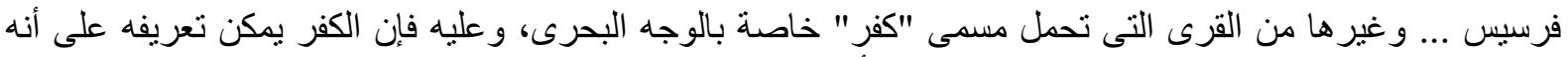

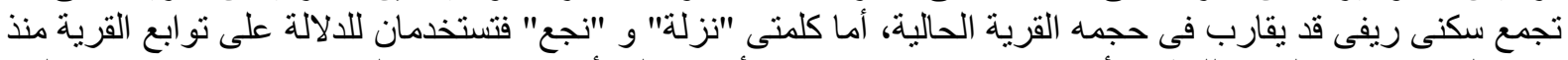

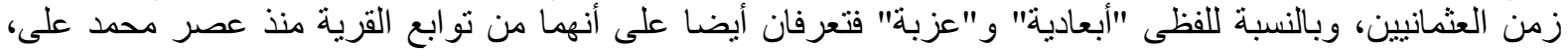

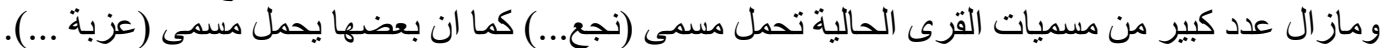

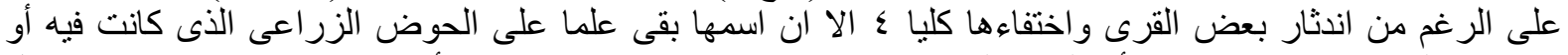

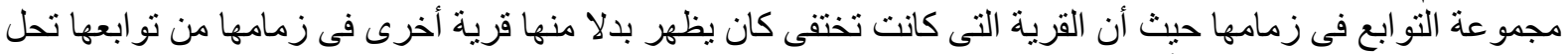

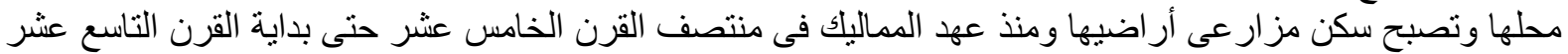

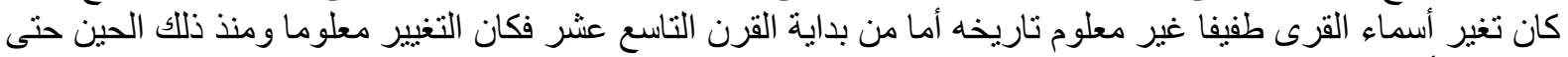

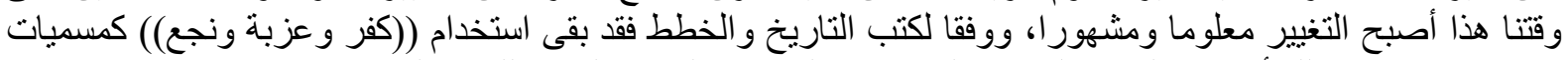
حتى يو منا هذا، وبذللك أصبح "الكفر و العزبة و النجع" هو المر ادف الحقيقى لتو ابع للقرية الدصرية. 


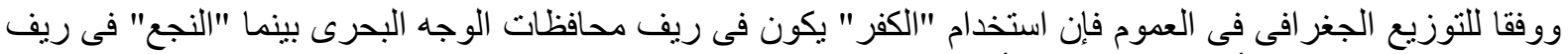

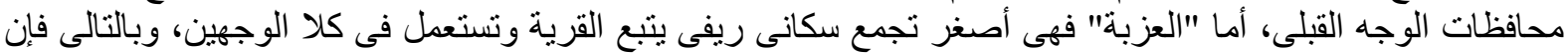

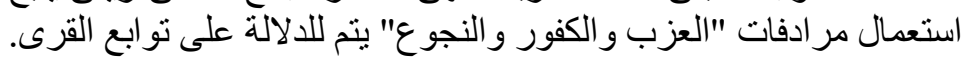

نشأة توابع القرى:-

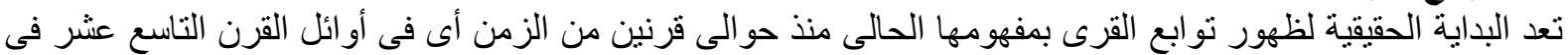

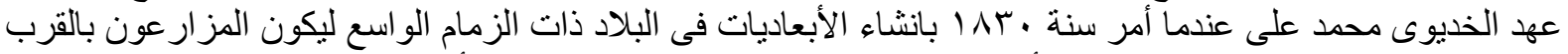

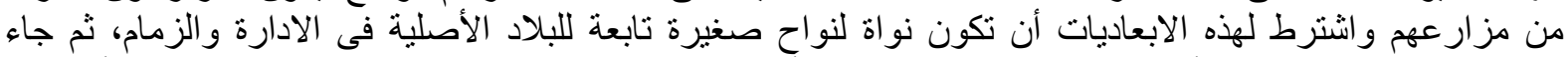

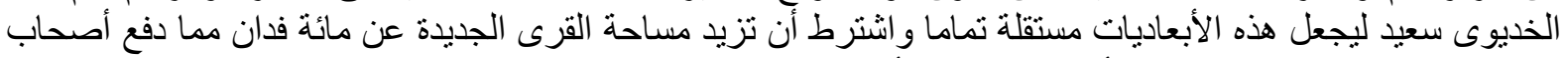

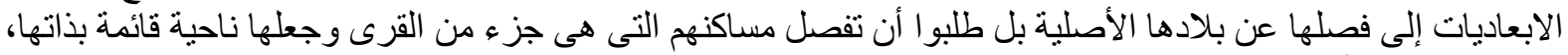

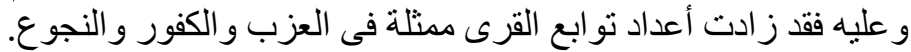

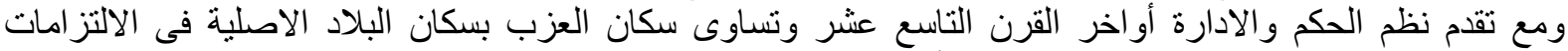

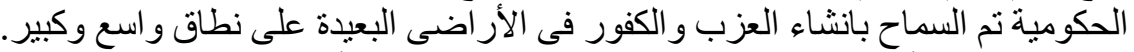

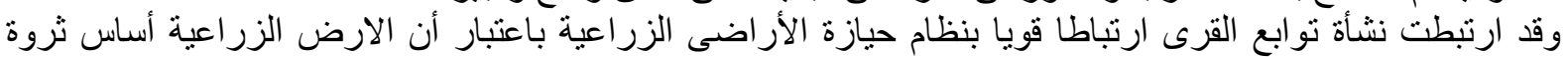

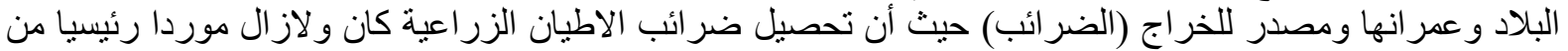

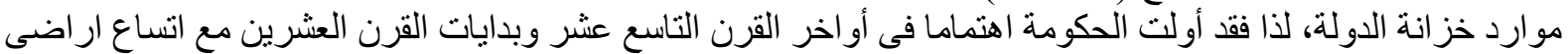

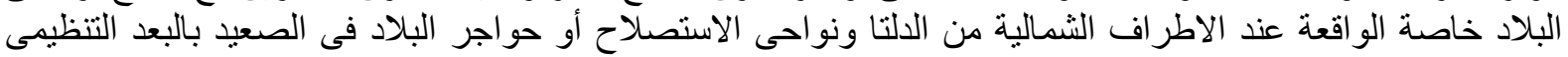

و الادارى.

التطور التاريخى لتوابع القرى:

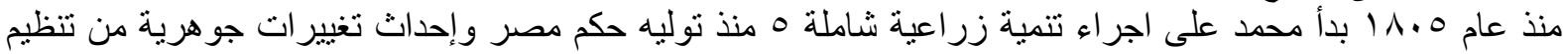

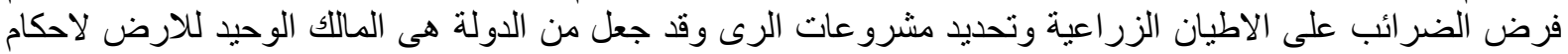

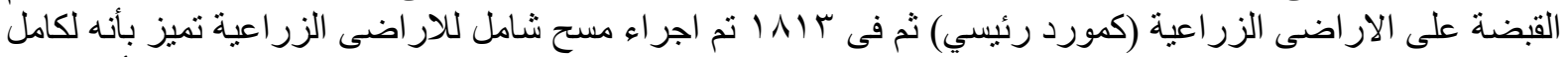

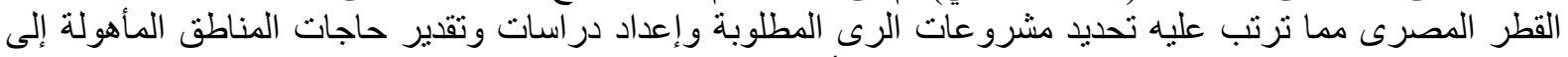

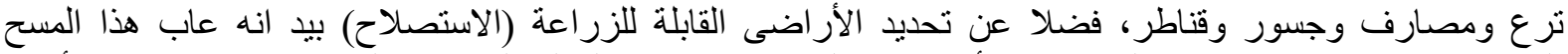

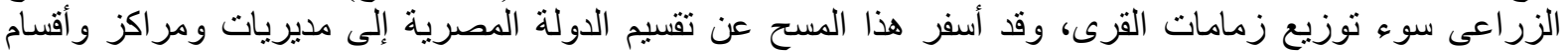

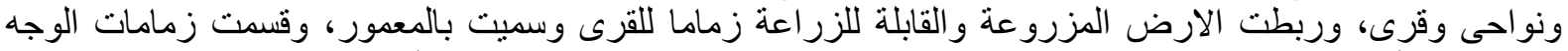

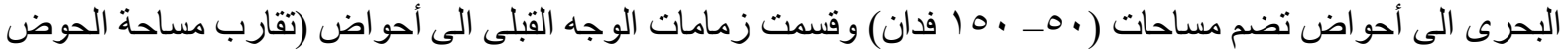

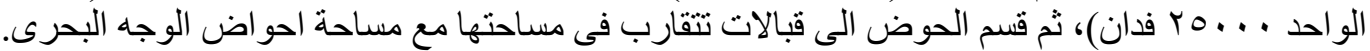

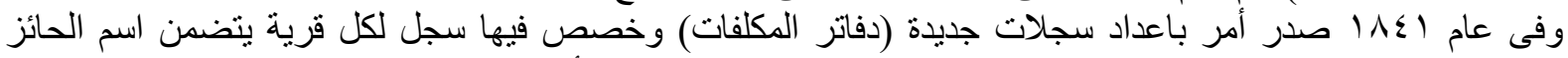

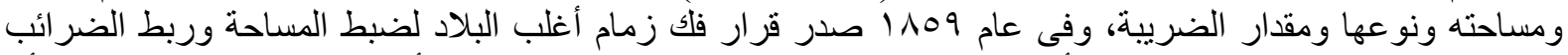

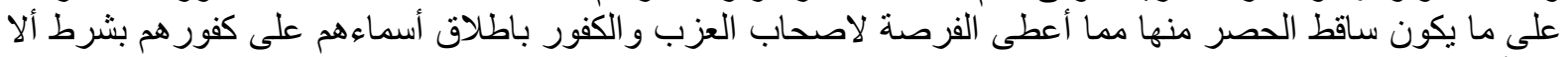

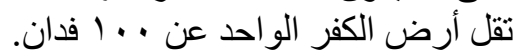

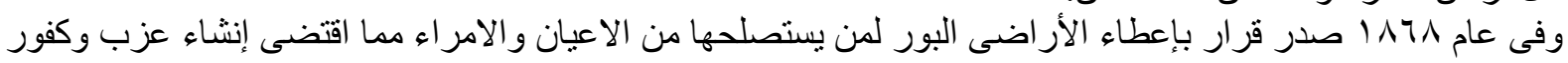

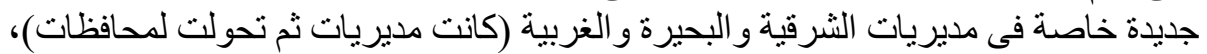

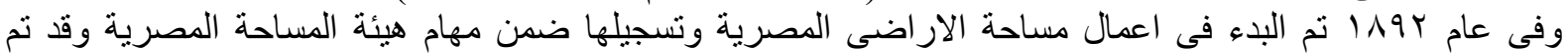

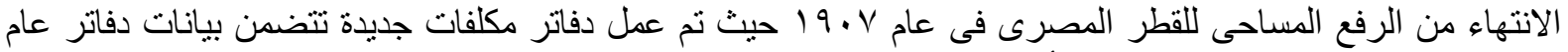

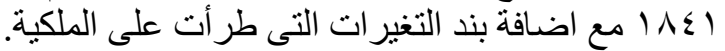

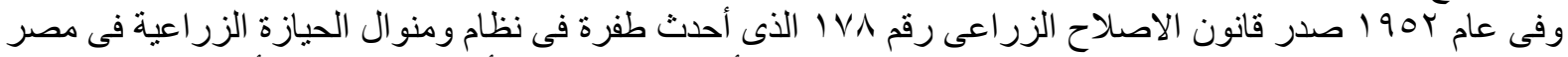

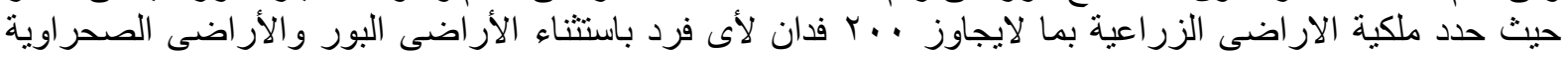

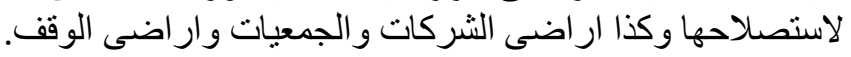

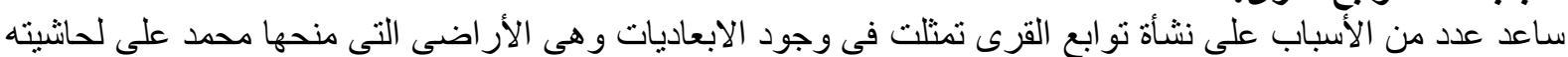

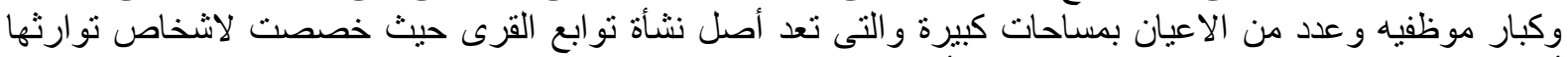

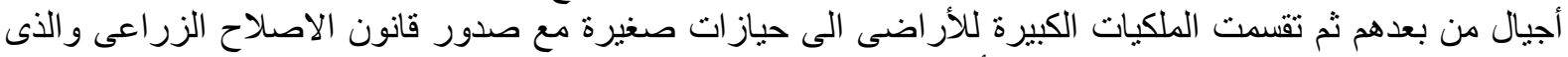

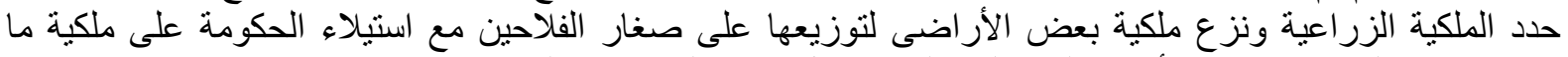

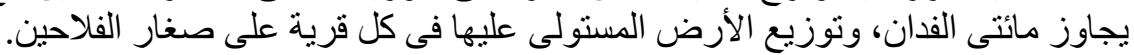

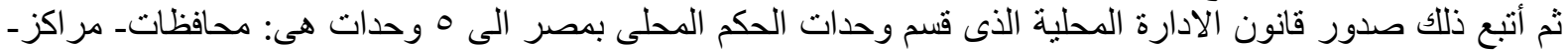

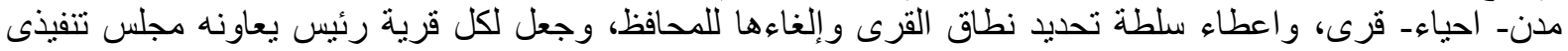
ويمارس المجلس الثعبى المحلى للقرية الرقابة على مختلف المرافق ذات الطابل الطابع المحلى كما أعطى لكل قرية لئل موارد 


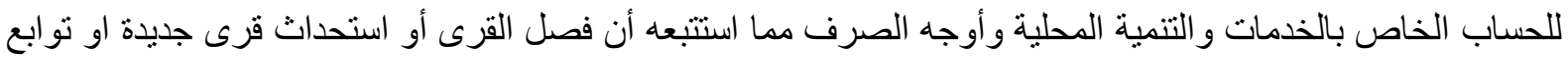
لللقرى بقرار من المحافظ المختص، وقد كان لهذا عظيم الاثر فى زيادة عدد توابع القرى حيث نم ذللك دون در اسة وانة التما لاعتبار ات و اهداف متعددة.

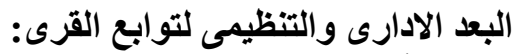

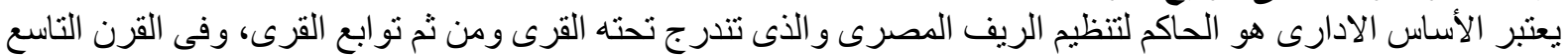

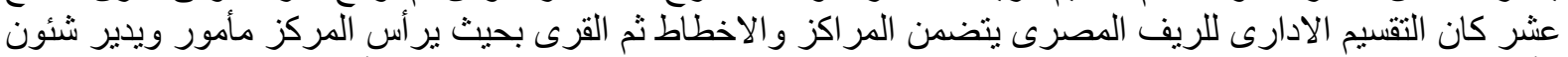

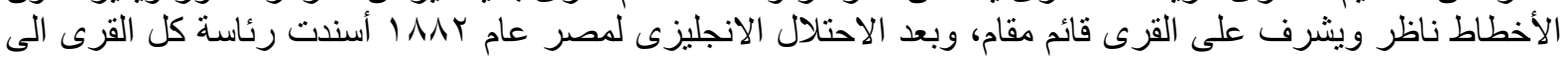

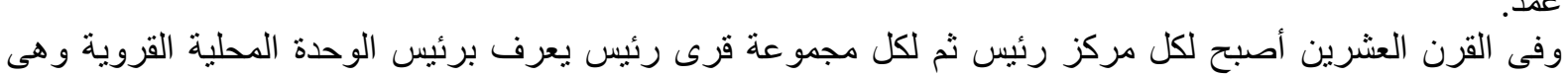

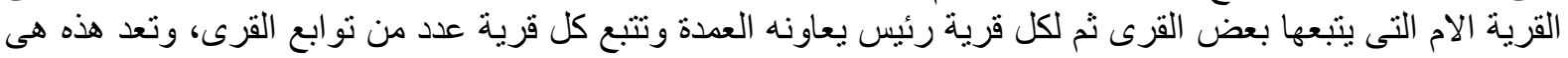

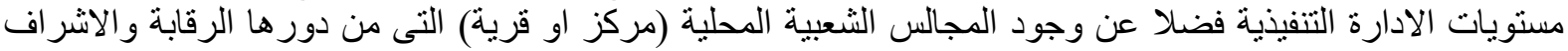
على الادارة التنفيذية.

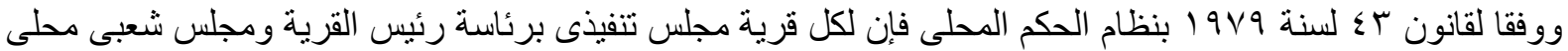

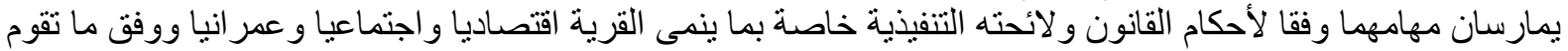

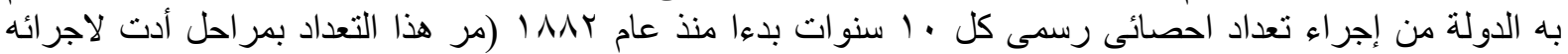

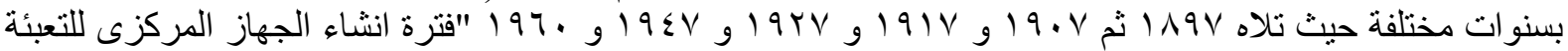
العامة والاحصاء و العمل بالقوانين المنظمة للعمل الاحصائى" ثم تعداد عام

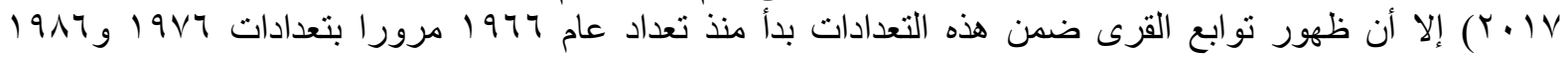

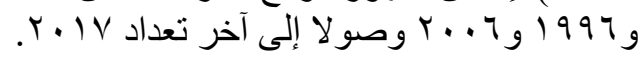

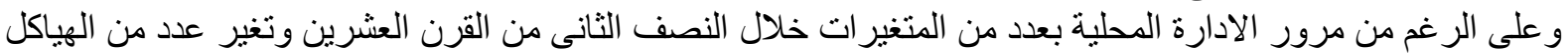

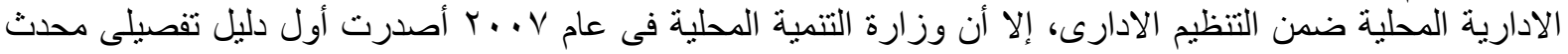

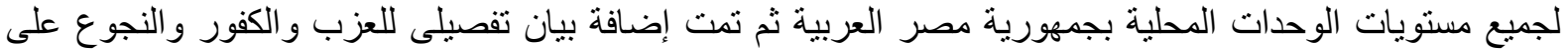

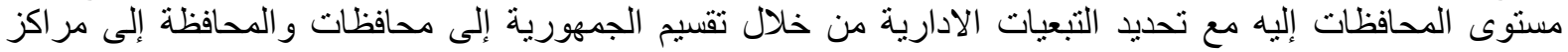

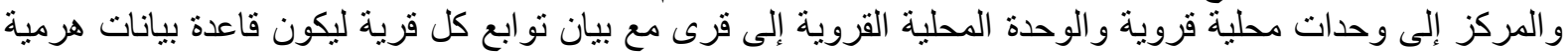

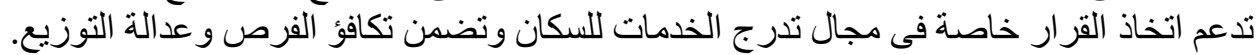

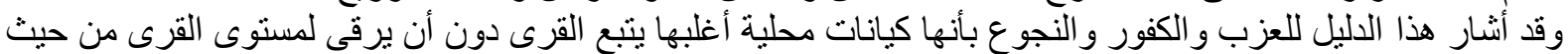
التعداد وتؤدى لها الخدمات من اقرب للعزب قرية أو وحدة محلية.

\section{شكل (1) تطور نظام ادارة الريف المصرى}

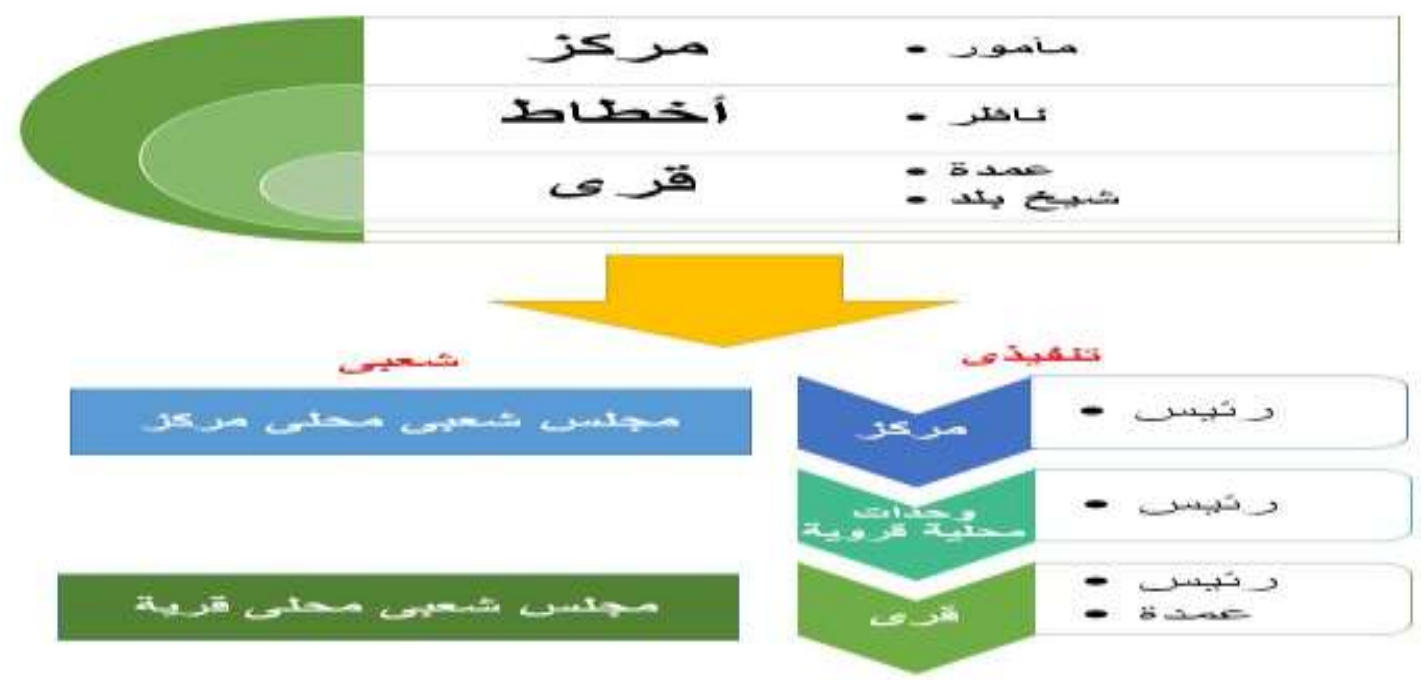

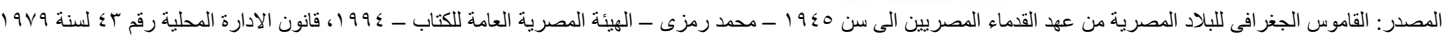

\section{الجانب الوصفى للبحث:}

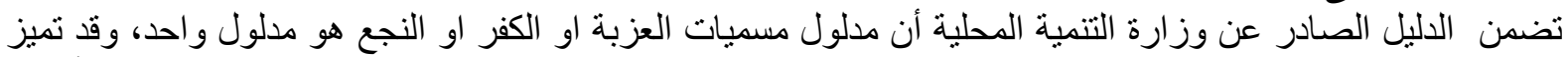

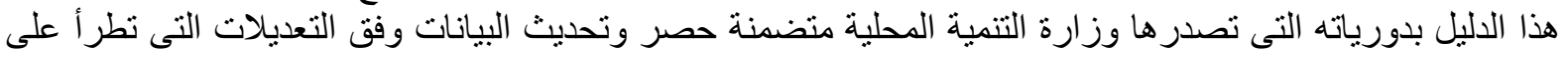

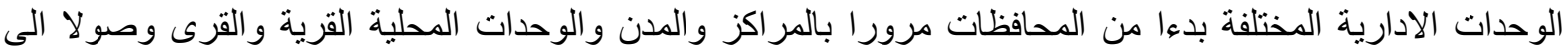

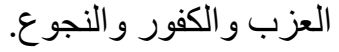




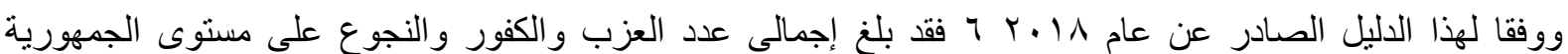

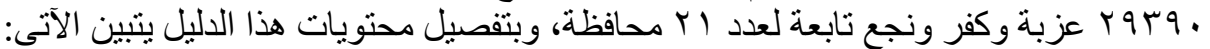

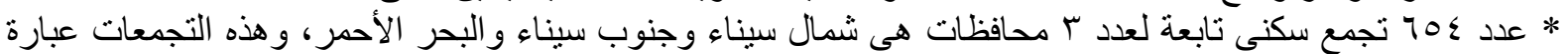

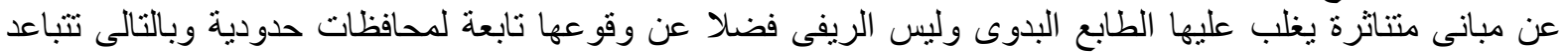

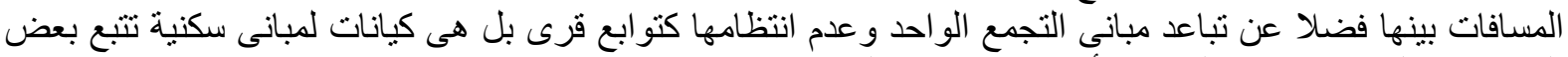
القرى بهذه المحافظات من الناحية الأمنية و الآدارية و التنظيمية.

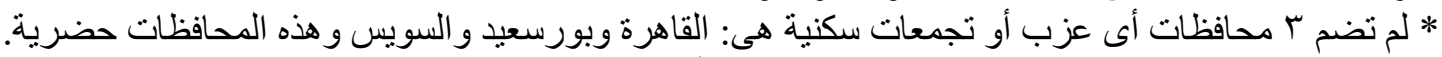

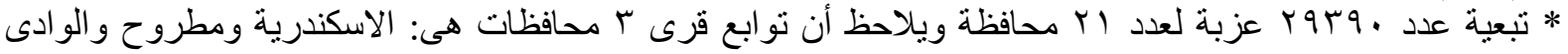

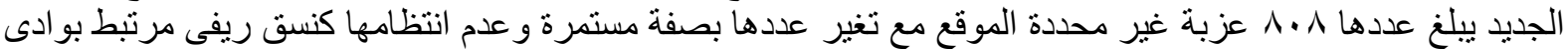

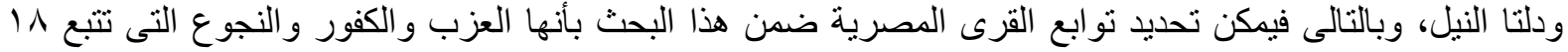

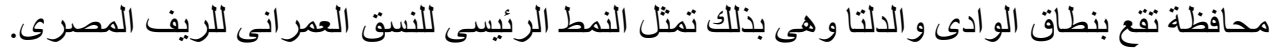

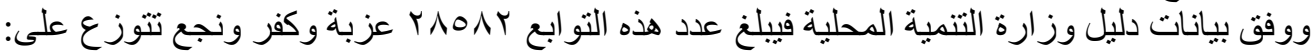

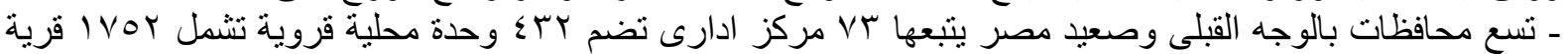

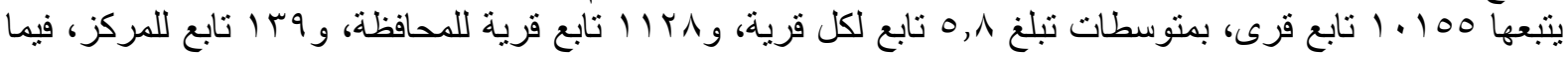

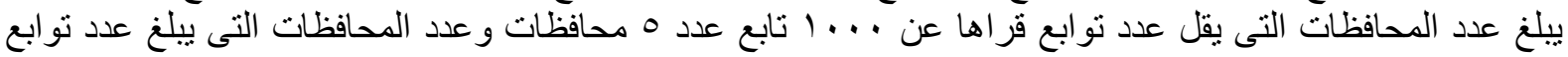

جدول (1) ت توابع قرى محافظات وجه قبلى

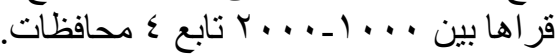

\begin{tabular}{|c|c|c|c|c|c|}
\hline \multirow{2}{*}{ واجمالى عدد العزب } & \multirow{2}{*}{ اجمالى عدد القرى } & \multicolumn{2}{|c|}{ الوحدات المحلية } & \multirow{2}{*}{ المحافظة } & \multirow[b]{2}{*}{ b } \\
\hline & & عدد الوحدات المحلية القروية & علد المراكز & & \\
\hline 1831 & 361 & 61 & 9 & المنيا & 1 \\
\hline 1771 & 163 & 63 & 6 & الفيوم & $r$ \\
\hline 1574 & 270 & 51 & 11 & سو هاج & $r$ \\
\hline 1402 & 152 & 41 & 9 & قنا & $\xi$ \\
\hline 888 & 235 & 55 & 11 & اسيوط & 0 \\
\hline 860 & 222 & 40 & 7 & بنى سويف & 7 \\
\hline 683 & 124 & 39 & 5 & أسوان & $\mathrm{v}$ \\
\hline 574 & 56 & 34 & 6 & الاقصر & $\Lambda$ \\
\hline 572 & 169 & 48 & 9 & الجيزة & 9 \\
\hline 10155 & 1752 & 432 & 73 & the & \\
\hline
\end{tabular}

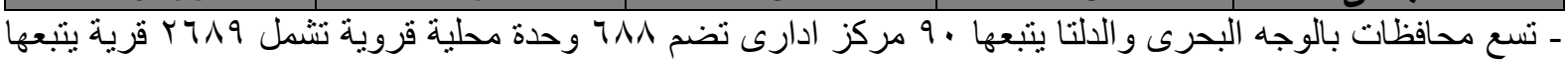

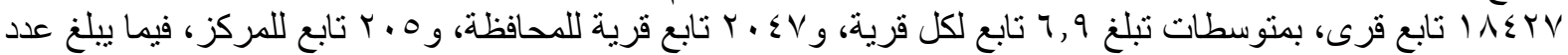

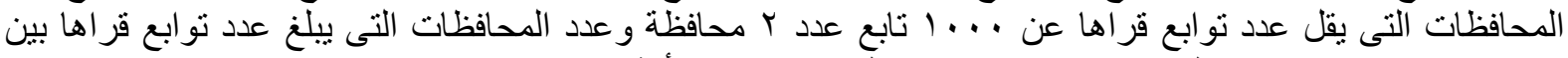

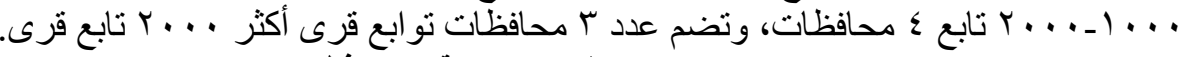

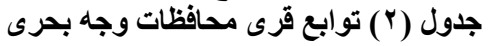

\begin{tabular}{|c|c|c|c|c|c|}
\hline \multirow{2}{*}{ والنجالى عدد والكفورب } & \multirow{2}{*}{ اجمالى عدد القرى } & \multicolumn{2}{|c|}{ الوحدات المحلية } & \multirow{2}{*}{ المحافظة } & \multirow[t]{2}{*}{$p$} \\
\hline & & عدد الوحدات المحلية القروية & عدد المراكز & & \\
\hline 5731 & 495 & 84 & 15 & البحيرة & 1 \\
\hline 3872 & 509 & 107 & 13 & الثرقية & $\bar{r}$ \\
\hline 2179 & 497 & 121 & 16 & الداقهلية & $\Gamma$ \\
\hline 1798 & 231 & 99 & 10 & كفر الثيخ & $\varepsilon$ \\
\hline 1193 & 321 & 69 & 8 & الغربية & 0 \\
\hline 1100 & 39 & 34 & 7 & الاسماعيلية & 7 \\
\hline 1022 & 317 & 77 & 9 & المنوفية & $\mathrm{v}$ \\
\hline 948 & 195 & 50 & 7 & القليوبية & $\Lambda$ \\
\hline 584 & 85 & 47 & 5 & دمياط & 9 \\
\hline 18427 & 2689 & 688 & 90 & ل ل لاجمالى ل ل & \\
\hline
\end{tabular}

وبنظرة عامة إلى كلا الجدولين يتضح الآتى:

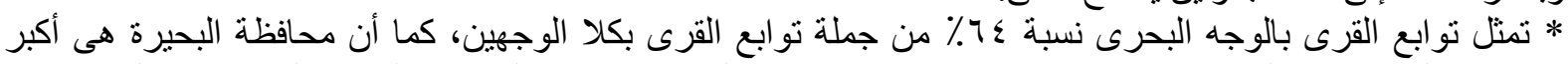

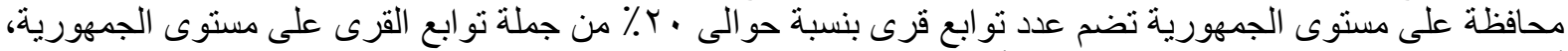

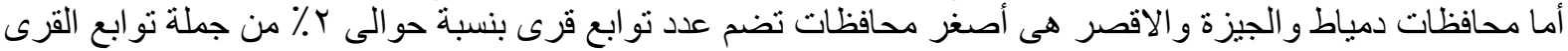

لكل محافظة. 


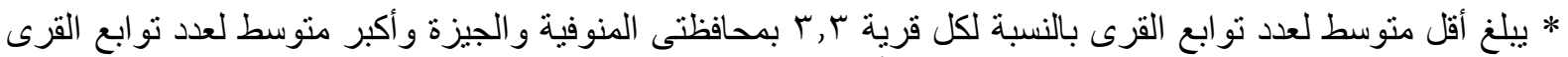

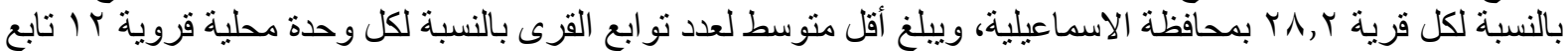

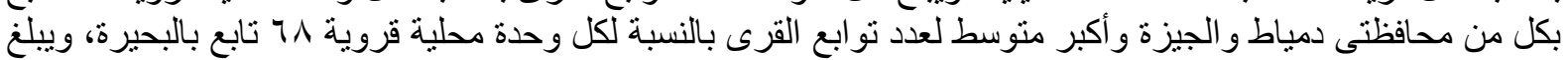

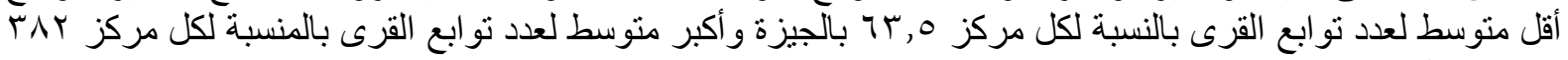

بمحافظة البحيرة.

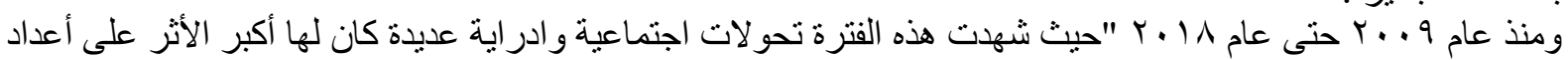

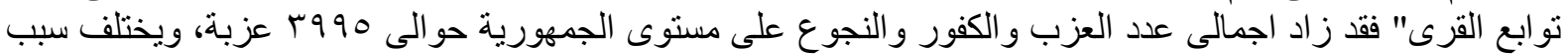

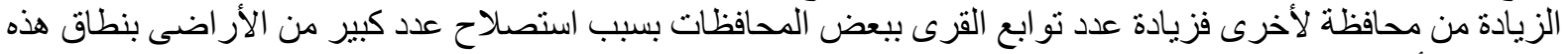

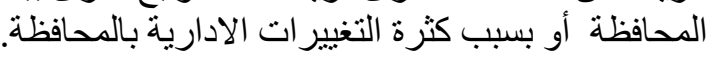

الاطار القانونى لتوابع القرى: الإن

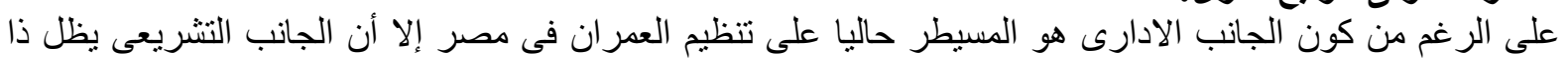

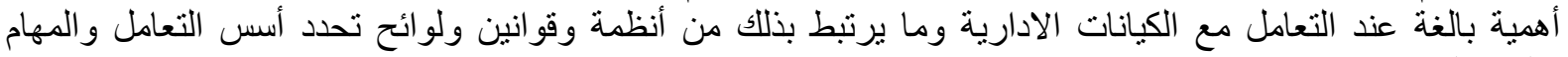
و والمسئوليات.

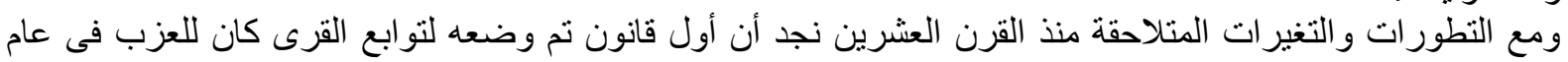

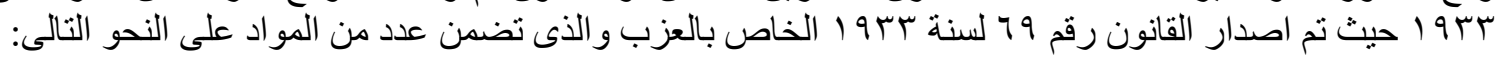

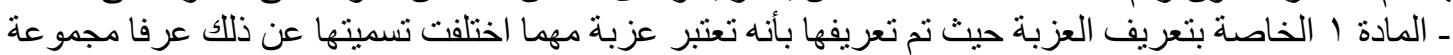

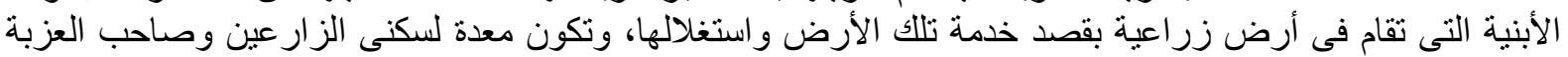

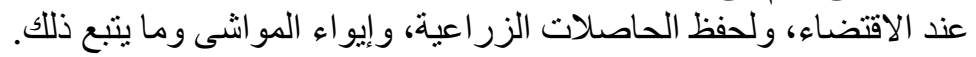

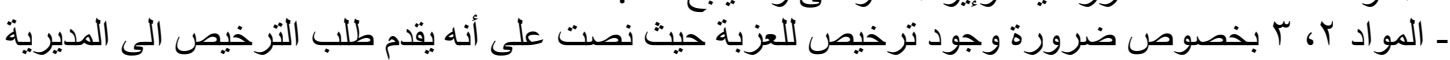

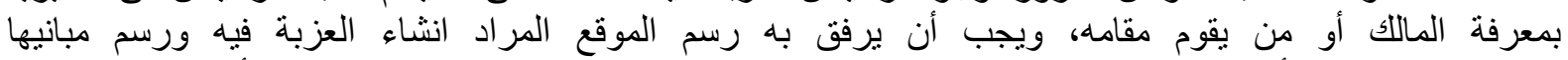

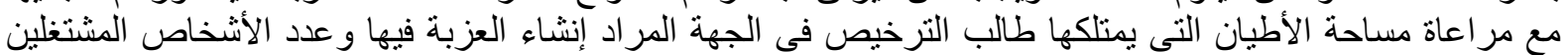

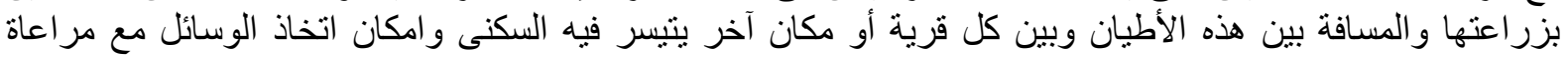

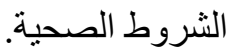

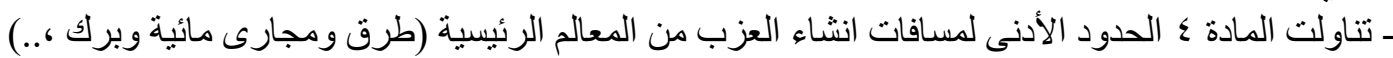

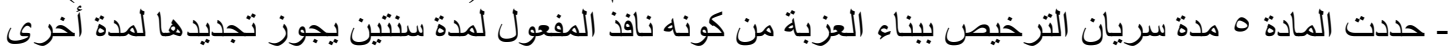

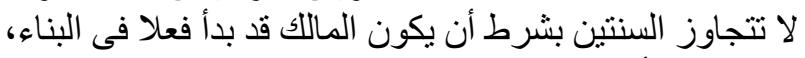

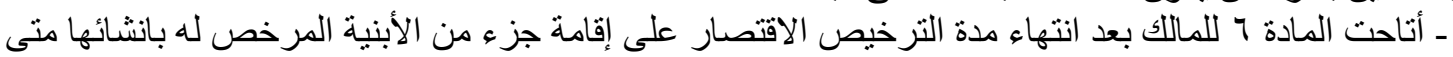

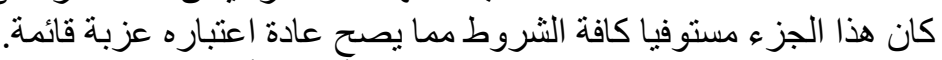

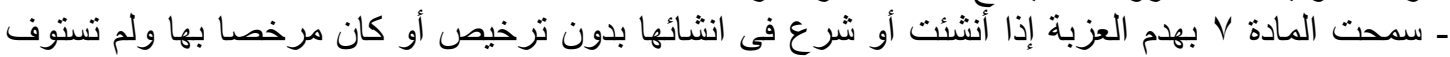

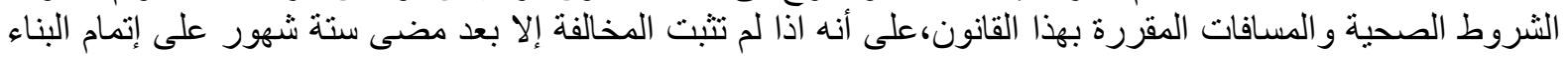

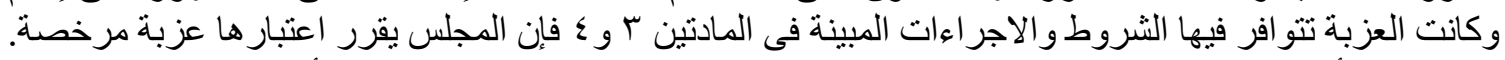

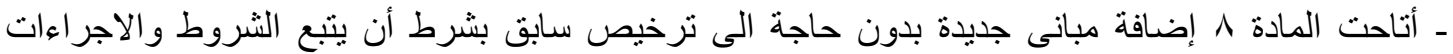

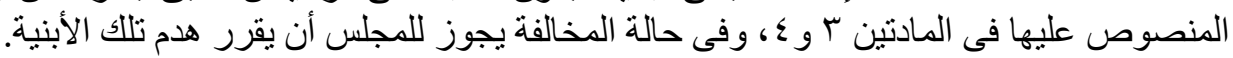

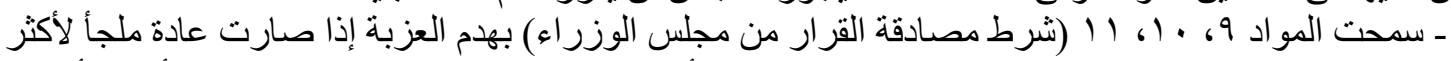

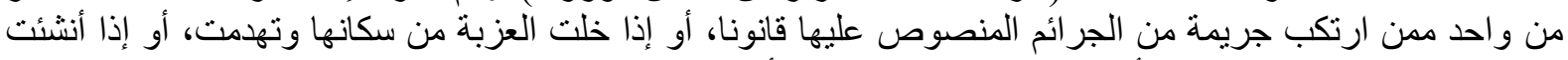

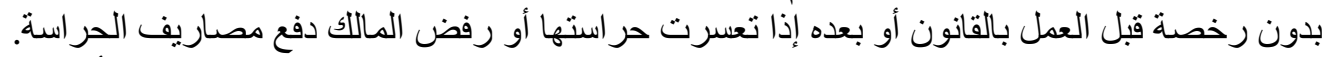

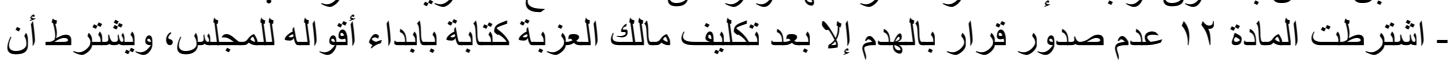

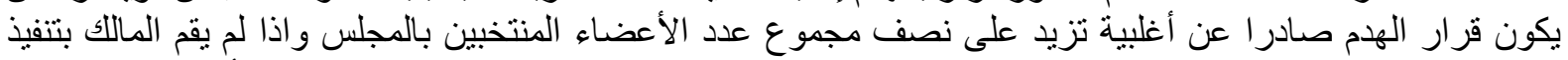

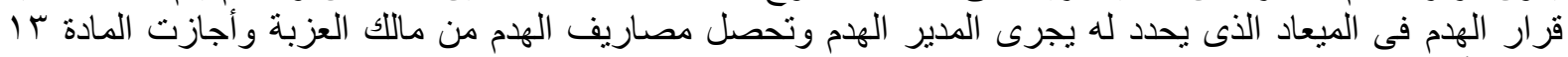

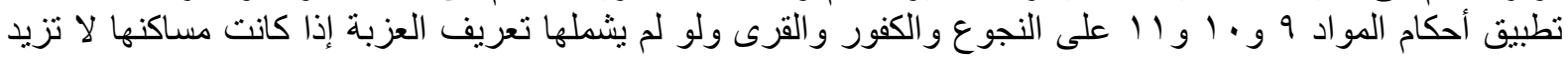
على عشرة.

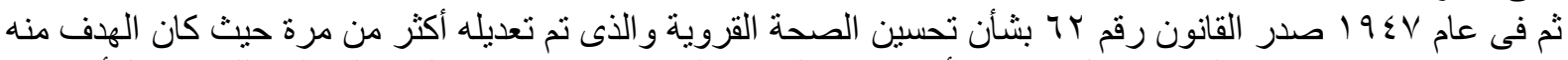

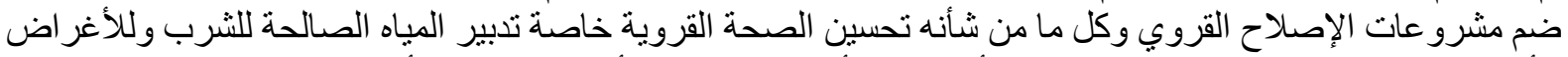

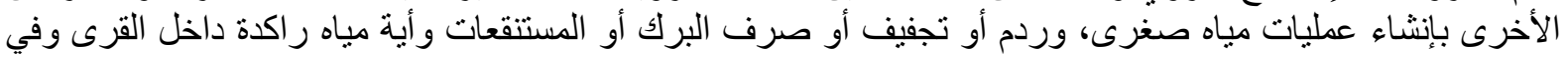

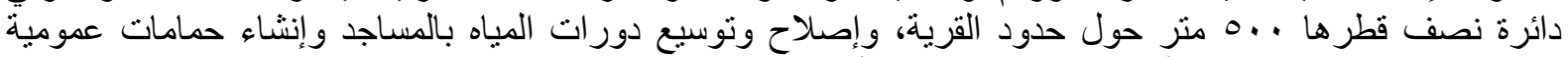

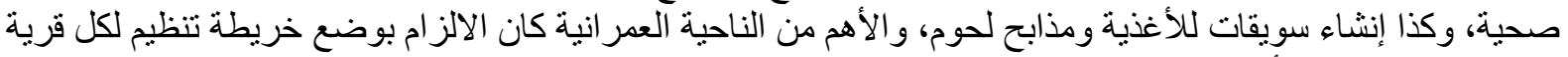

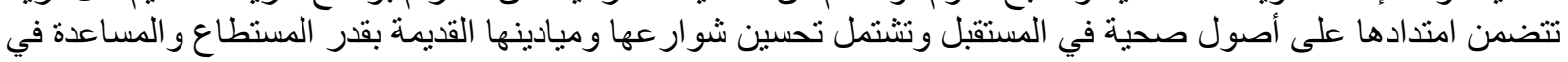

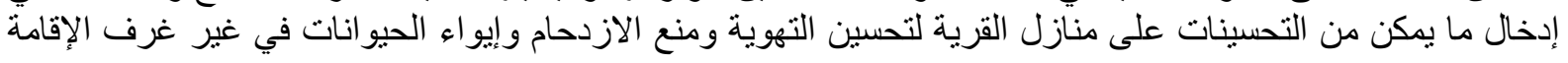


و ايجاد المر احيض القروية البسيطة في المنازل، وتوفير خدمات رعاية الأمومة والطفولة وكذا عيادة طبية مجانية بكل

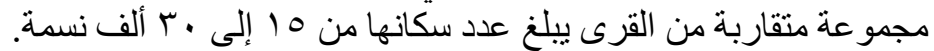

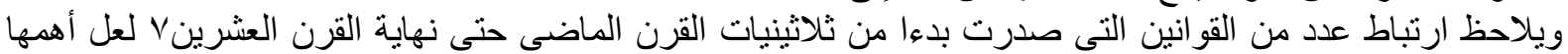

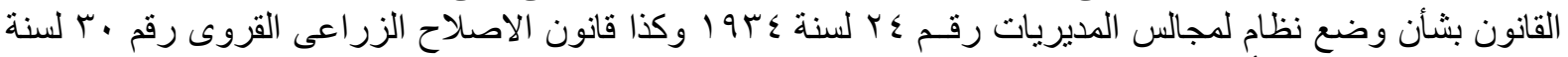

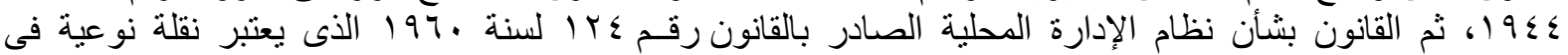

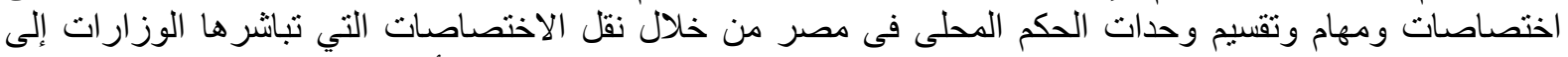

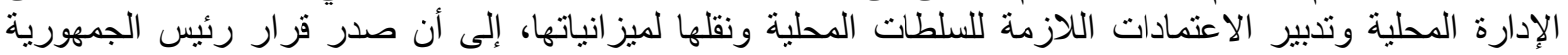

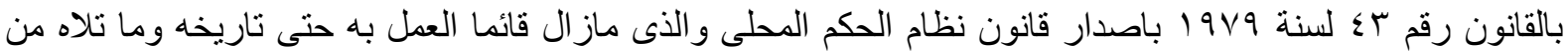

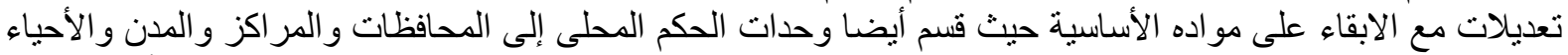

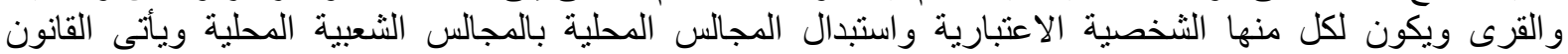

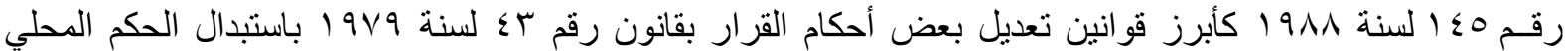
بالإدارة المحلية.

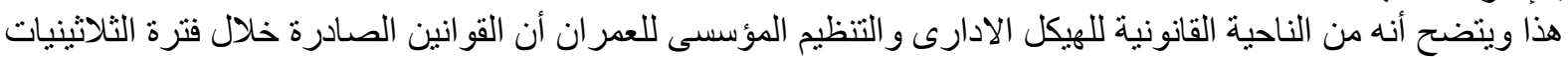

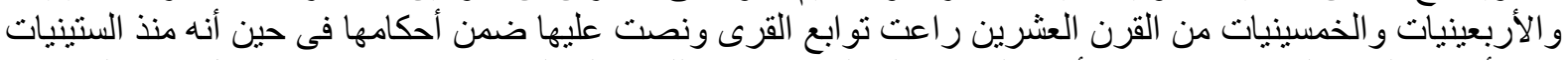

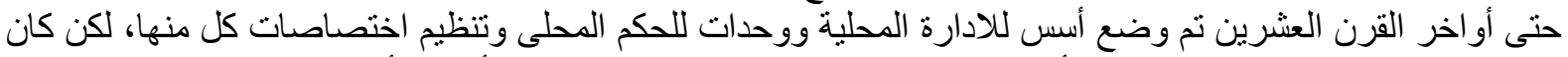

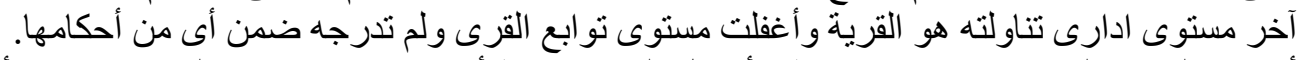

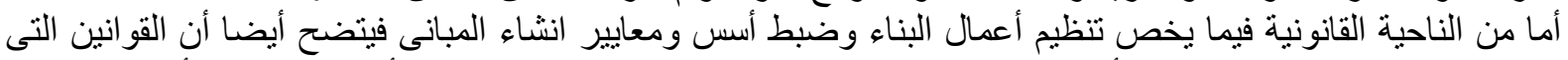

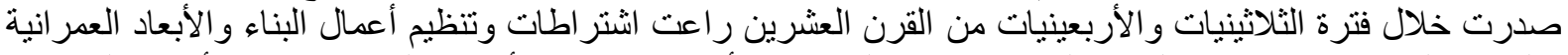

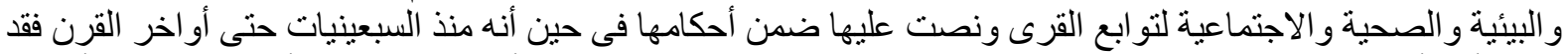

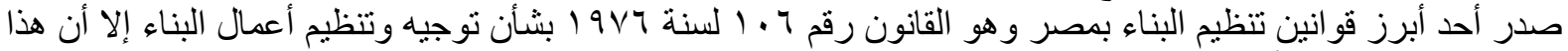

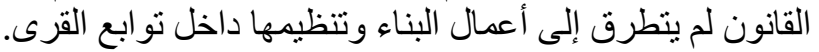

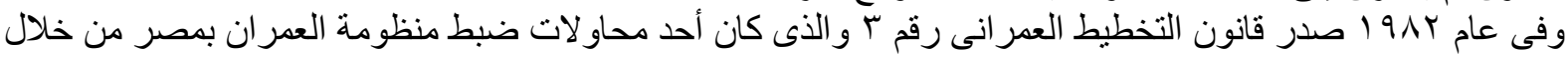

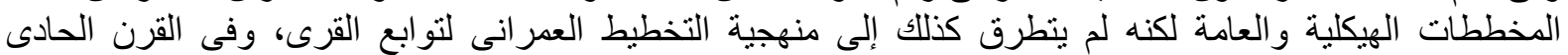

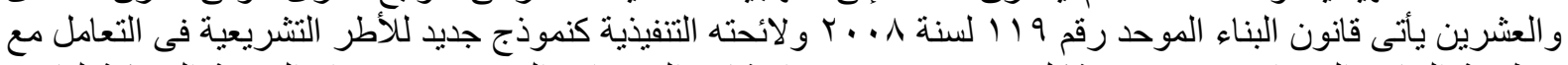

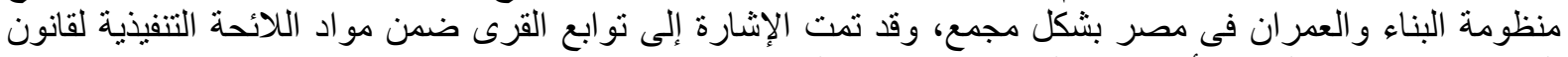

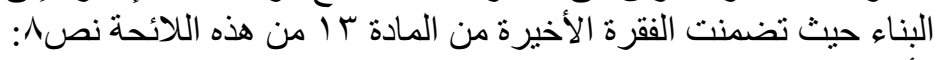

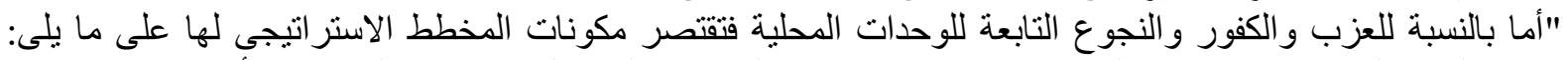

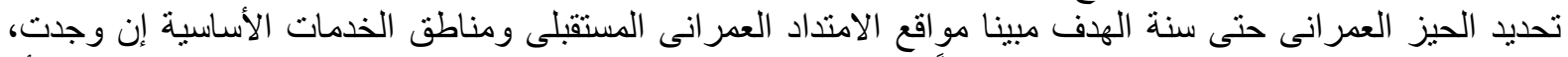

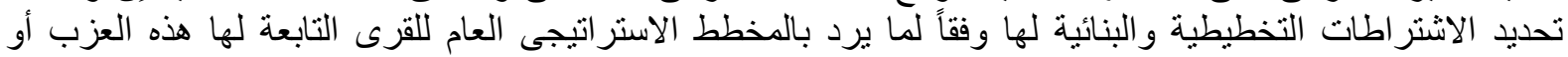

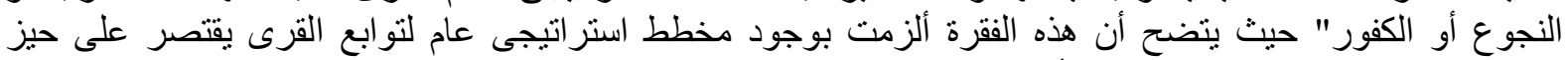

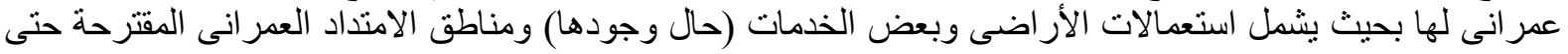

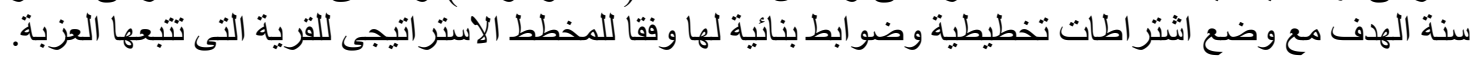

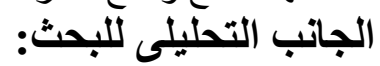
أسفرت الدراسة التحليلية التىى أجراها البها الباحث لتوابع القرى المصرية الواقعة اداريا ضمن المحافظات الريفية لمصر

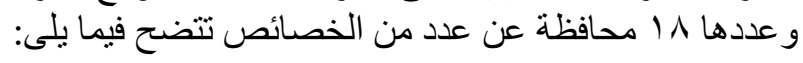

\section{الخصائص السكانية لتوابع القزى:}

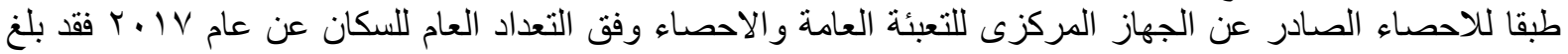

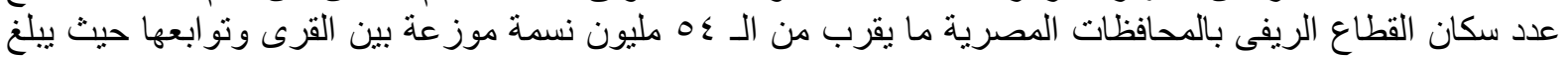

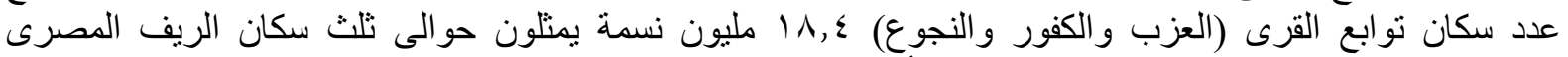

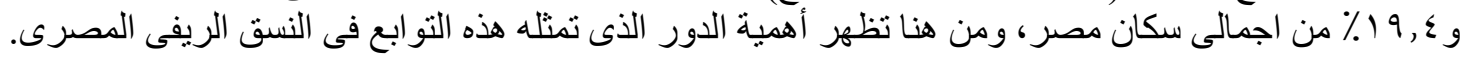

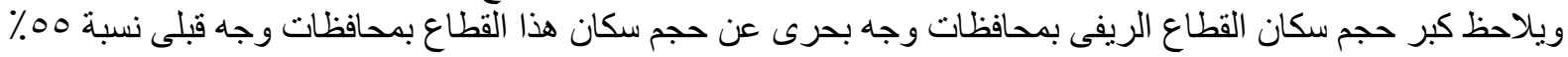

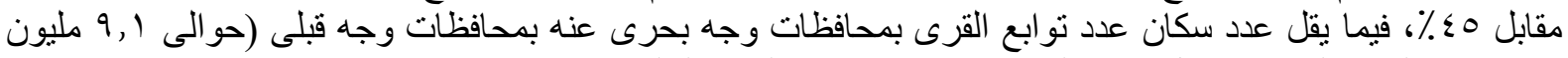

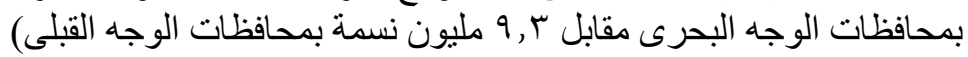

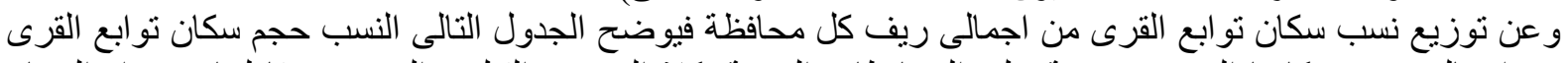

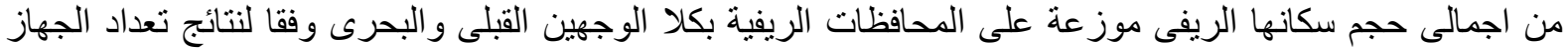

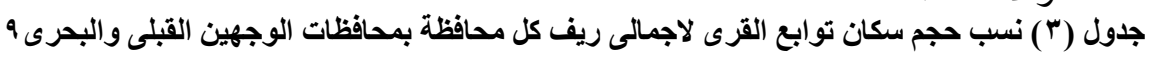

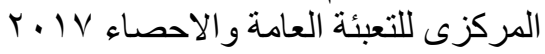

\begin{tabular}{|c|c|c|}
\hline نسبة سكان توابع القر & نسبة سكان توابع القرى لاجمالى سكان & 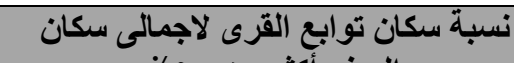 \\
\hline
\end{tabular}

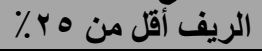

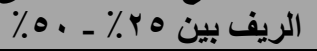

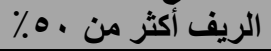


دور توابع القرى المصرية "العزب والكفور والنجوع" فى تثكيل النسق العمرانى الريفى المصرى

\begin{tabular}{|c|c|c|c|c|c|}
\hline النسبة & المحافظة & النسبة & المحافظة & النسبة & المحافظة \\
\hline$\% \wedge \wedge, v$ & rا 1 القليوبية & $\% \leqslant 7,1$ & V V.الفيوم & $\% \vee V$ & 1.الاسماعيلية \\
\hline$\% 1 \wedge$ & ع ا.الدقهلية & $\% \varepsilon \cdot, q$ & ^.الشرقية & $\%$ & (قنا \\
\hline$\% 17,7$ & 10 الغزبية & $\%$ \% & 9.كفر الثيخ & $\% \bullet 9,1$ & r.|الاقصر \\
\hline$\% 19$ & 17 .المنوفية & $\%$ & ـ ا.المنيا & $\% \Delta \leqslant, Y$ & ع.البحيرة \\
\hline$\% 10,1$ & V الجيزة & $\% r q, v$ & 11.|سيوط & $\%$ or & •.سوهاج \\
\hline$\% 9, \varepsilon$ & 1 1.دمياط & $\% r q, r$ & r ا بنيى سويف & $\% 01, r$ & 7.اسوان \\
\hline
\end{tabular}

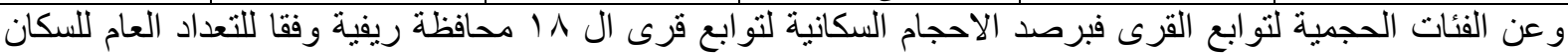

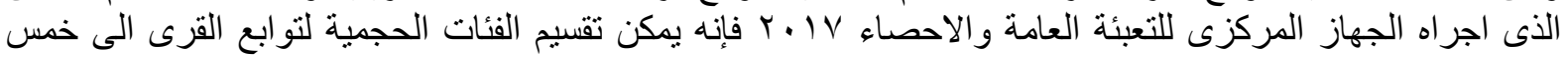

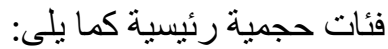

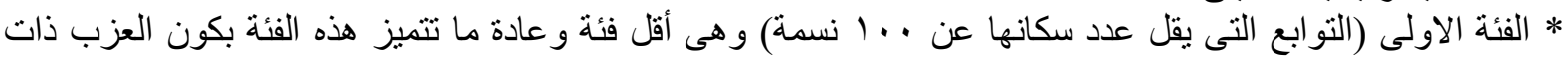

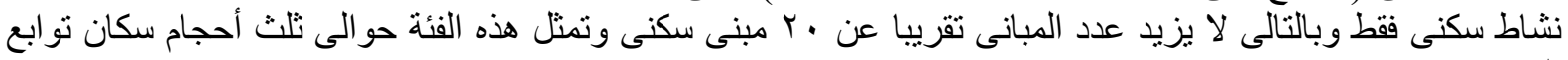

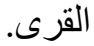

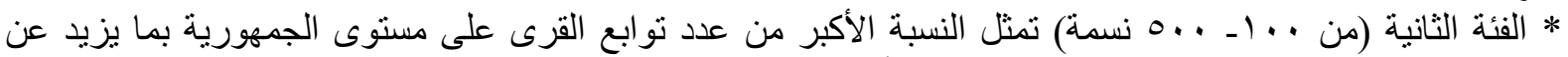

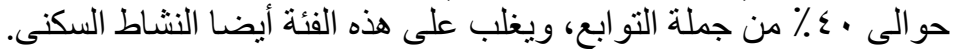

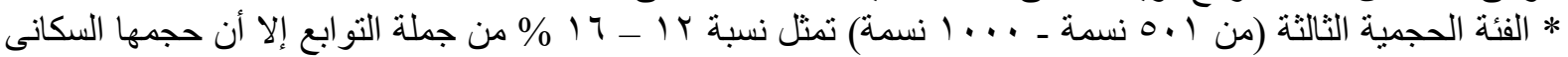
يجعلها ضمن الثريحة المتلى لاحجام التوابع، وغالبا ما تتميز هذه الفئة بوجود إحدى الخدمات كمسجد أو مدرسة للتعليم التئ

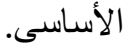

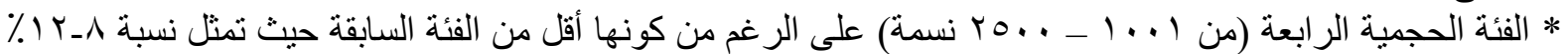

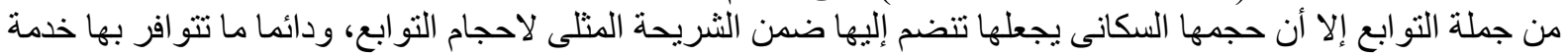
تعليمية هى مدرسة تعليم اساسى الأنى

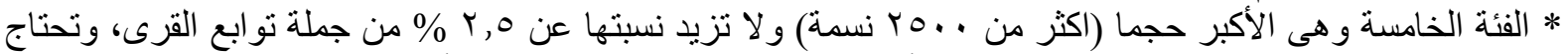

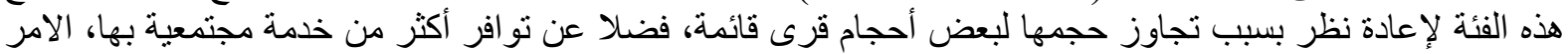

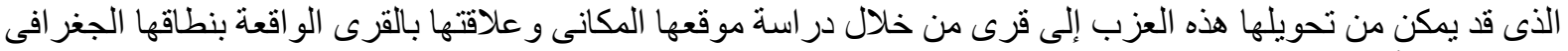

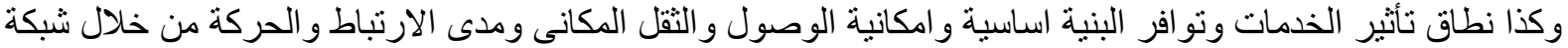

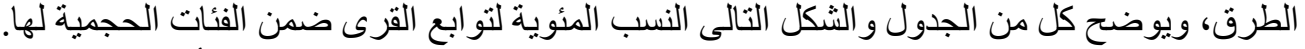

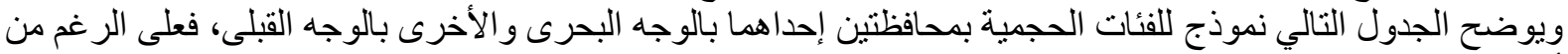

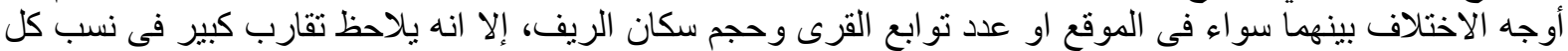
فئة حجمية لكلا المحافظتين.

جدول (؛ ) الفئات الحجمية لسكان توابع القرى بمحافظة كفر الثيخ ومحافظة بنى سويف

\begin{tabular}{|c|c|c|c|c|c|}
\hline 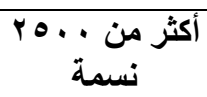 & 'P نسمة & 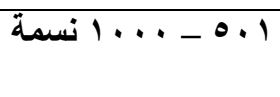 & 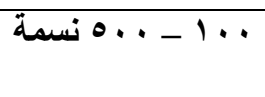 & أقل من · . 1 نسمة & عدد العزب \\
\hline$\%$ & $\%$ & $\%$ & $\%$ & $\%$ & النسبة المئوية \\
\hline$\leq 1$ & 203 & 351 & 912 & 650 & \multirow{2}{*}{ (الوجه البحرى للخحافظات } \\
\hline r\% & $9.4 \%$ & 16.3 & $42.3 \%$ & $30 \%$ & \\
\hline $1 \leqslant$ & 10 & IrV & rol & rAr & \multirow{2}{*}{ 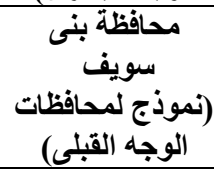 } \\
\hline $1,7 \%$ & $\% 9,9$ & $\% 1 \leq, \wedge$ & $\% \varepsilon \cdot \wedge$ & $\% . r Y, q$ & \\
\hline
\end{tabular}

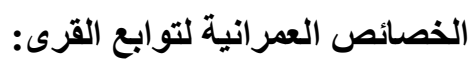

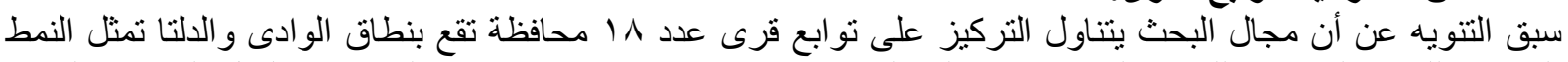

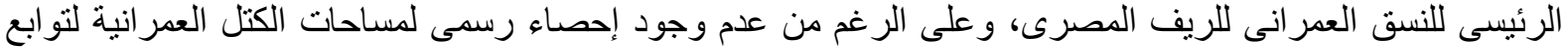

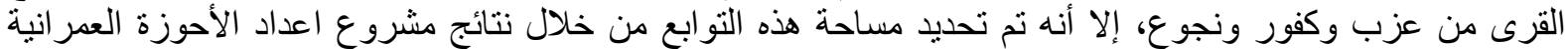

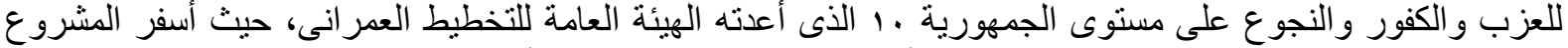

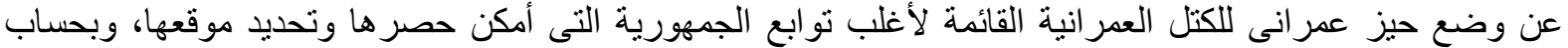

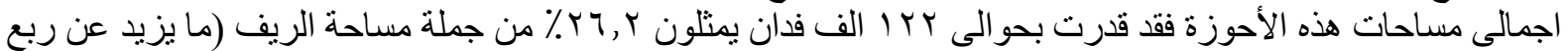

مساحة الريف المصرى). 


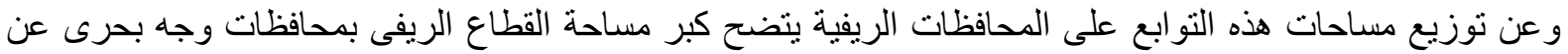

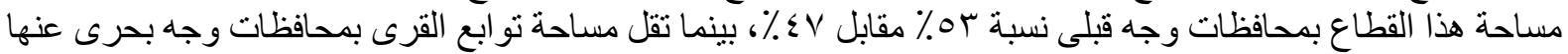

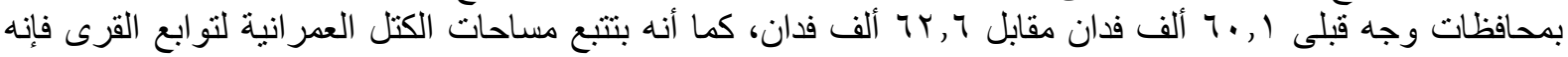

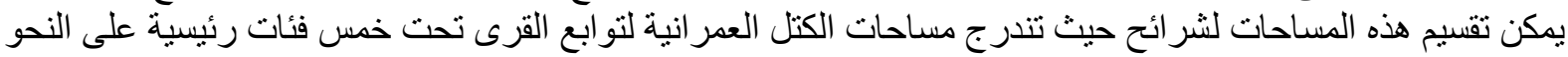
التالى: * الفئة الاولى (تقل مساحتها عن ا فدان) وتتضمن جميع نوابع القرى التى لا تتجاوز مساحة كتلتها العمر انية ا فدان،

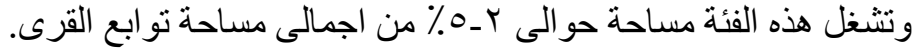

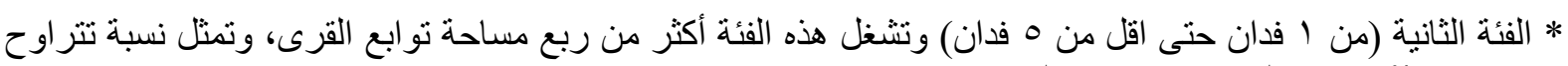

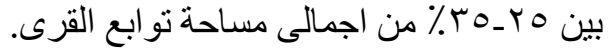

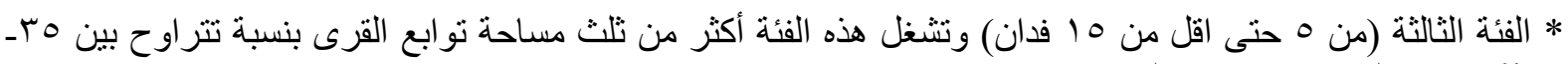

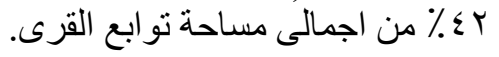

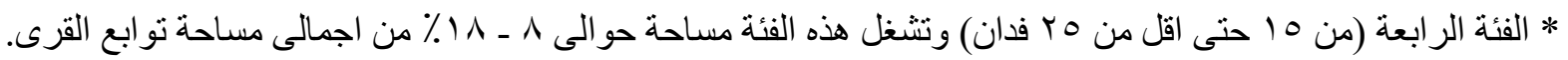

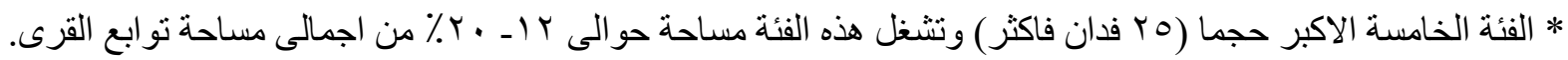

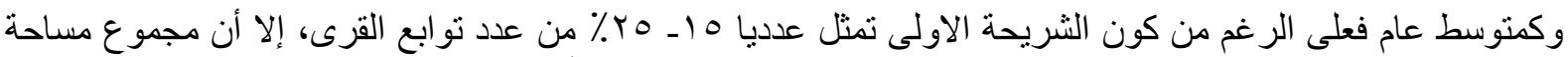

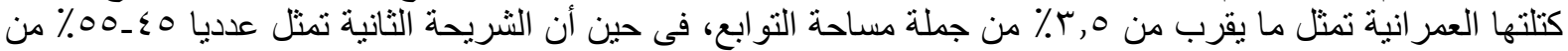

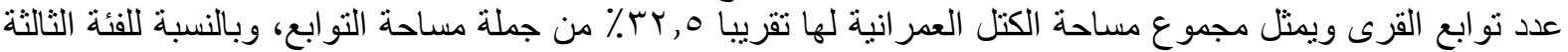

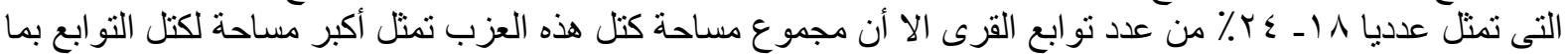

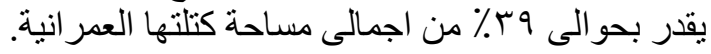

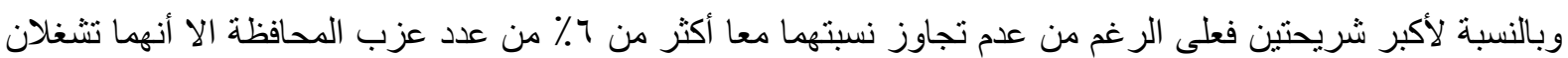

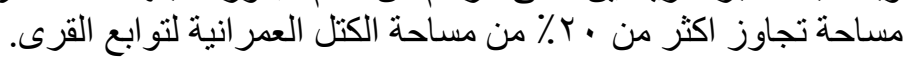

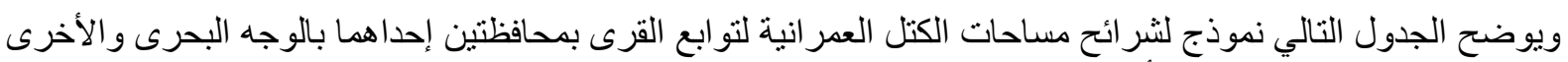

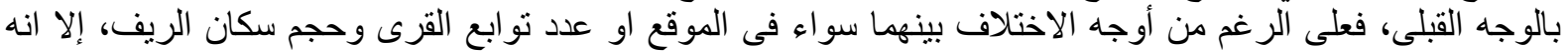
يلاحظ تقارب كبير فى نسب مساحة كل فئة لكلا المحافظتين.

جدول (0) فئة مساحة توابع القرى ونسبتها المئوية بمحافظة المنوفية ومحافظة أسيوط

\begin{tabular}{|c|c|c|c|c|c|}
\hline هـ فذان فاكثر & 10 ـ فاقل من 0 & هـ ف اقل من 10 & 1 - اقل من ه & أقل من 1 فدان & (الوجوذج لمحافظة البحرى) \\
\hline 10 & $r$. & YIV & $\Delta \wedge V$ & TVT & عدد العزب \\
\hline$\Delta q \Psi,\{$ & $M O \Lambda, 0$ & $I V V V, \Lambda$ & $1 \leqslant \vee \wedge, 1$ & $10 \mathrm{~V}, 0$ & المساحة بالفدان \\
\hline$\% 1 r, 7$ & $\% \wedge, Y$ & $\% \varepsilon \cdot, v$ & $\% r r, q$ & $\%, 4$ & النسبة المئوية للمسياحة \\
\hline هץ فذان فاكثر & 10 ـ فدان من هب & هـ فـل من 10 & 1 ـ فدان من 0 & أقل من 1 فدان & (الوحوذج لمحافظة أنسيوطات \\
\hline$r T$ & $r q$ & 194 & 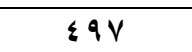 & 170 & عدد العزب \\
\hline$\Lambda r_{0, Y}$ & VYo,r & 1774,1 & IrY, r & $1 \cdot \varepsilon, 0$ & المساحة بالفدان \\
\hline$\% \wedge \wedge, Y$ & $\% 17$ & $\% r q, 7$ & $\% r q, q$ & $\%, r$ & النسبة المئويةة للمساحة \\
\hline
\end{tabular}

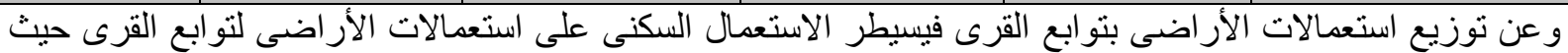

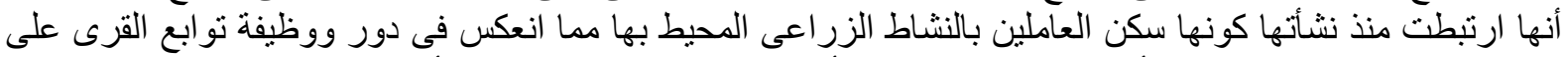

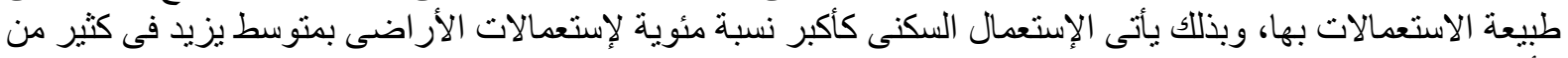
الأحيان عن 70\% من إجمالي مسطح الكتلة العمر انية.

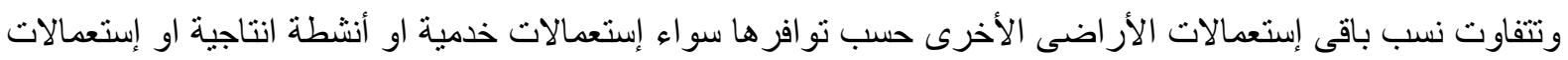

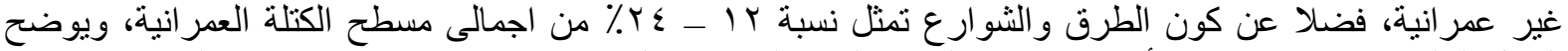
الثكل التالى نماذج لاستعمالات أراضى بعض العز العزب التابعة لقرية ابو الخزر بمركز ابو حمص بمحافظة البحيرة 


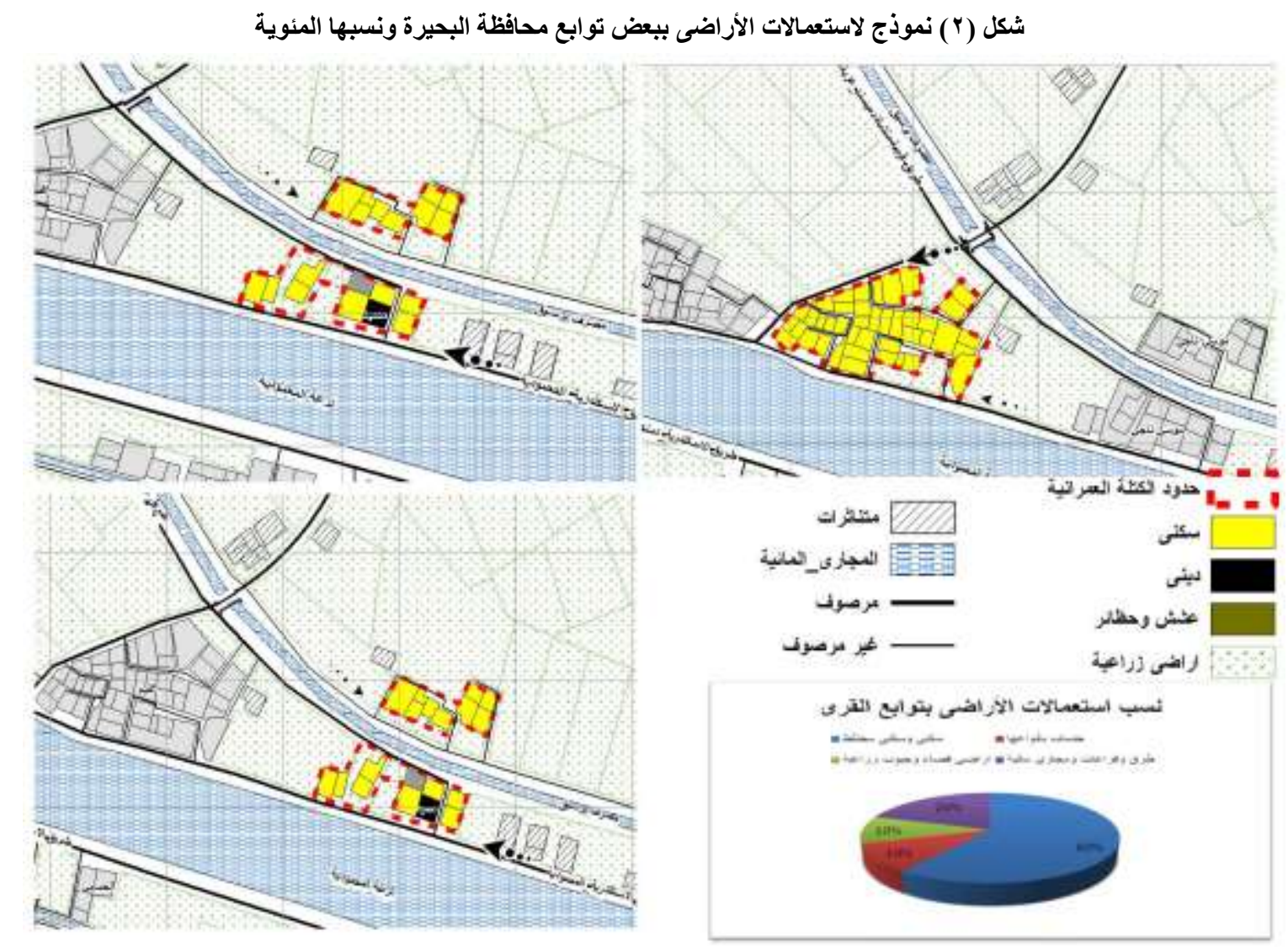

المصدر: وزارة الاسكان والمرافق والمجتمعات العمرانية، الهيئة العامة للتخطيط العمرانى، مشروع إعداد الأحوزة العمرانية للعزب والكفور والنجوع التابعة

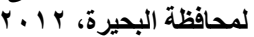

وبالنسبة للنسيج العمر انى لهذه التو ابع فلا يوجد نسيج عمر انى موحد يمكن توصيفه لكل تو ابع القرى بل لكّ لكل محافظة نمط

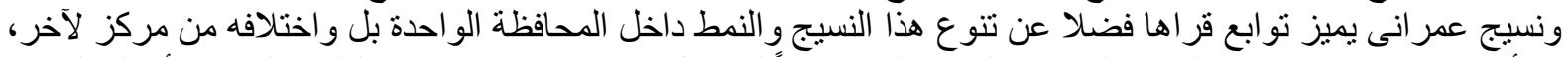

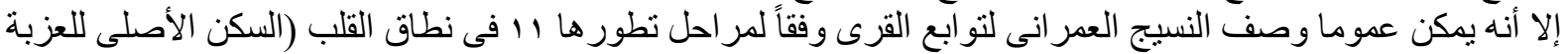

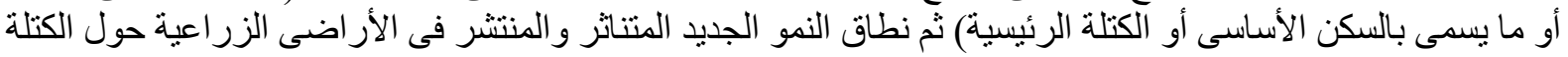

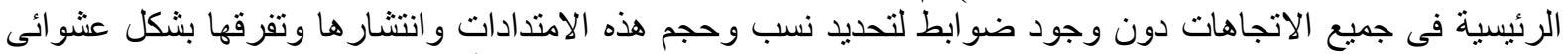

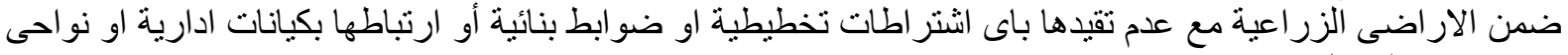

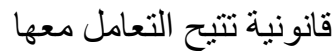

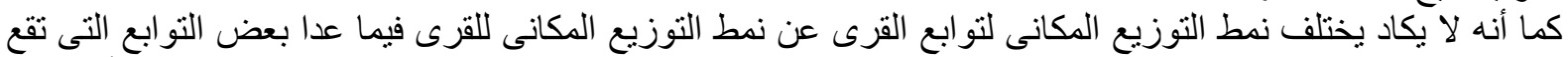

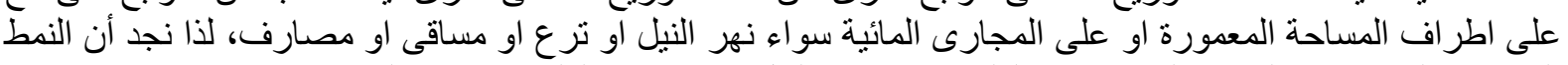

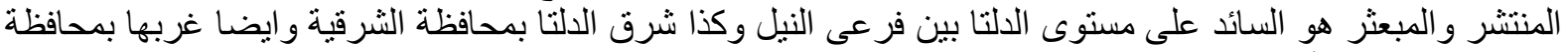

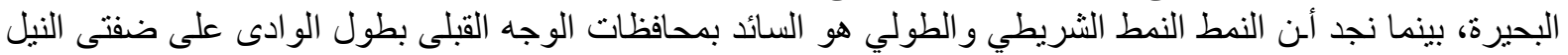

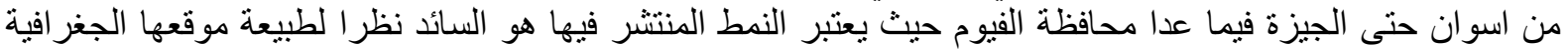

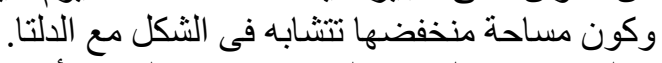

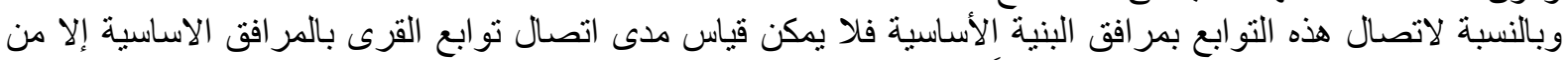

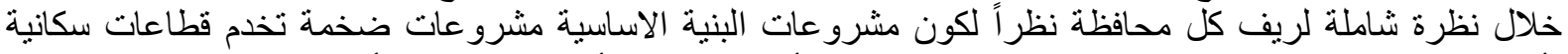

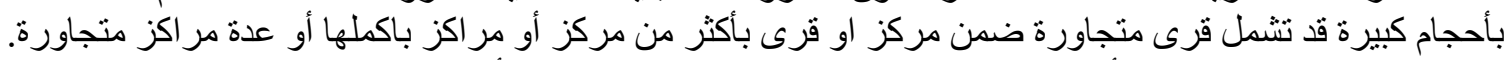

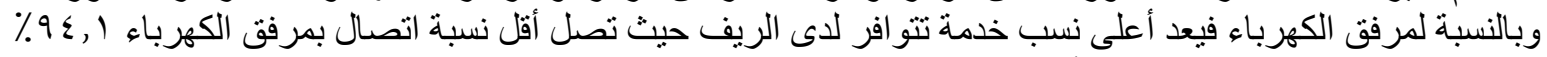

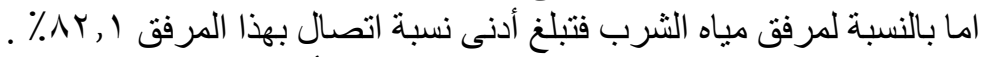
وبالنسبة للصرف الصحى فتبلغ نسب الاتصال به أدنى نسب قياسا بباقى مر افق البنية الاساسية نظر العدا لعدم تو افر شبكات

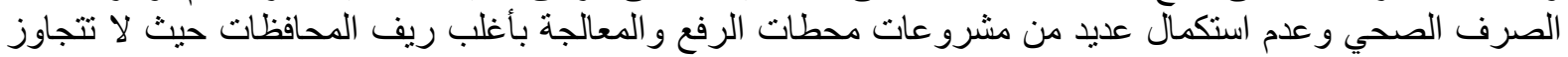
0 لاستكمال الامداد بمر افق البنية الاساسية.

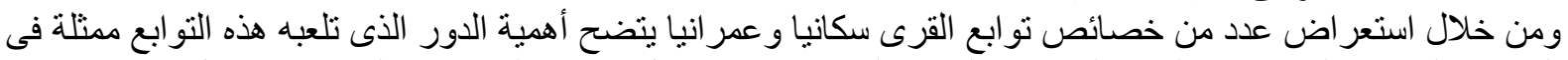

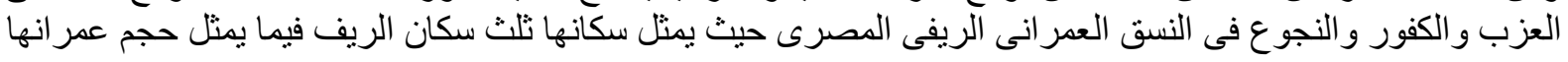


ربع حجم عمران الريف مع ضخامة أعدادها وانتشار ها على مستوى جميع المحافظات الريفية الأمر الذى ينطلب تسليط

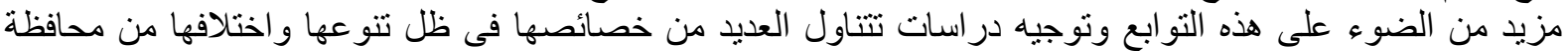

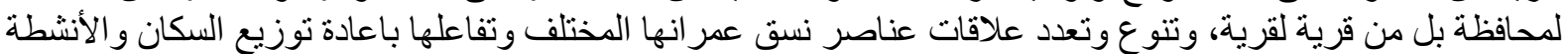

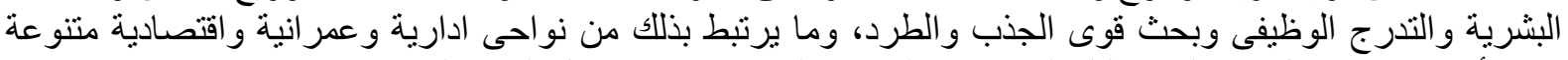

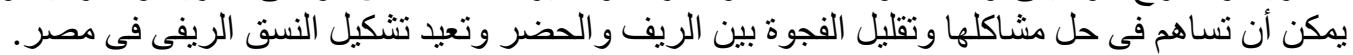

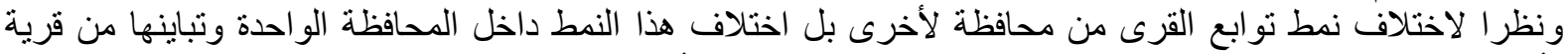

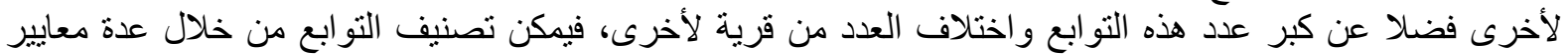

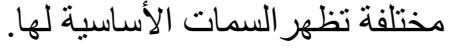

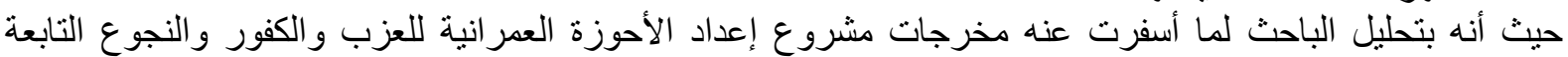

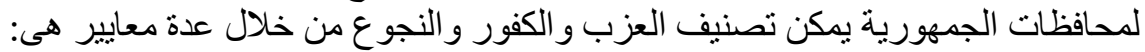

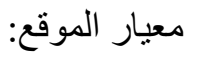

ويتضمن r انماط رئيسية هى: وسط احو اض زراعية ـ على محاور الطرق والمجارى المائية ـ على ضفاف نهر النيل او

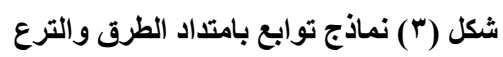

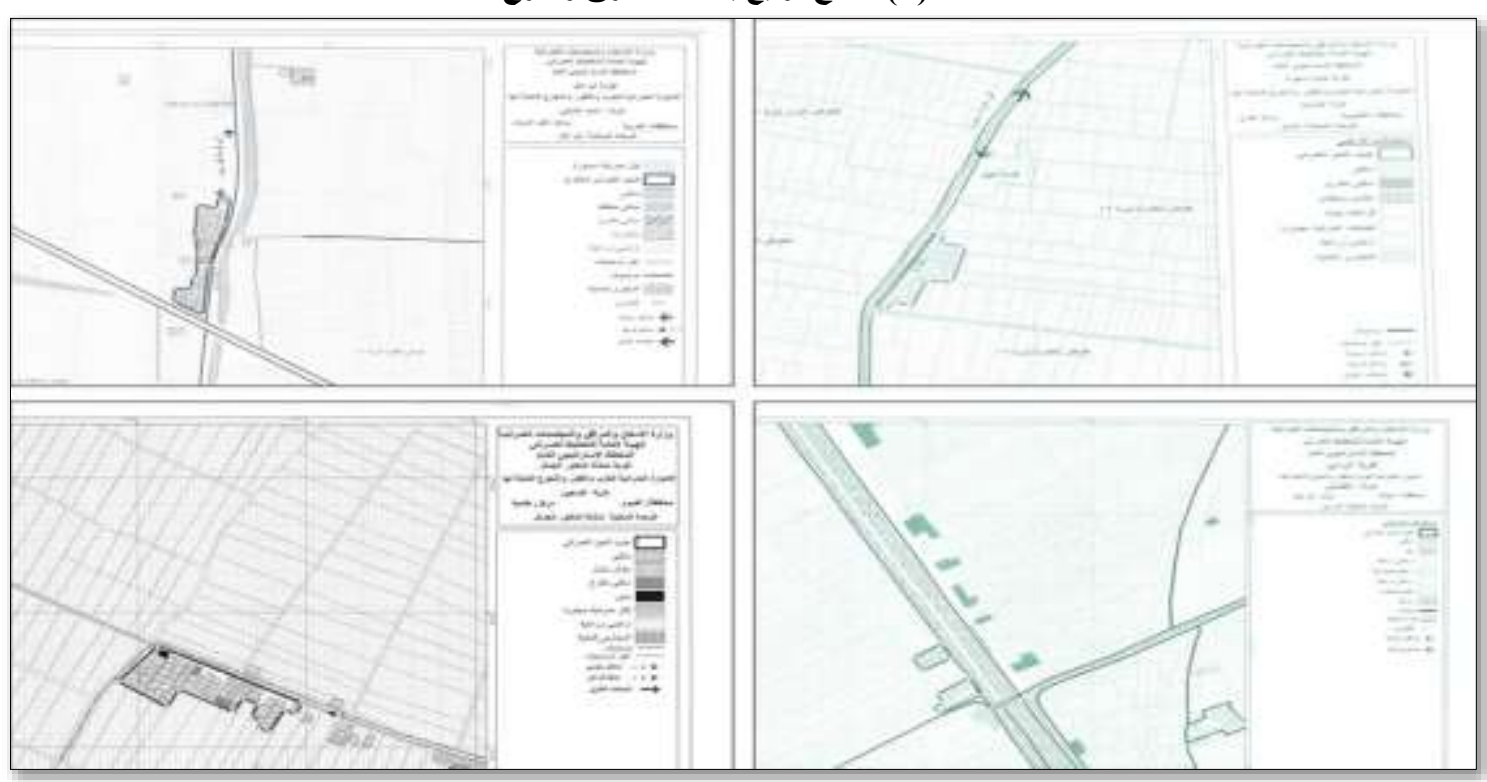

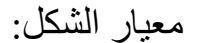

ويتضمن r انماط رئيسية هى: شكل هنسى منتظم مثل مربع او مسنطيل او مثلث - شريطى - غير منتظم أو عضوى 
دور توابع القرى المصرية "العزب والكفور والنجوع" فى تثكيل النسق العمرانى الريفى المصرى

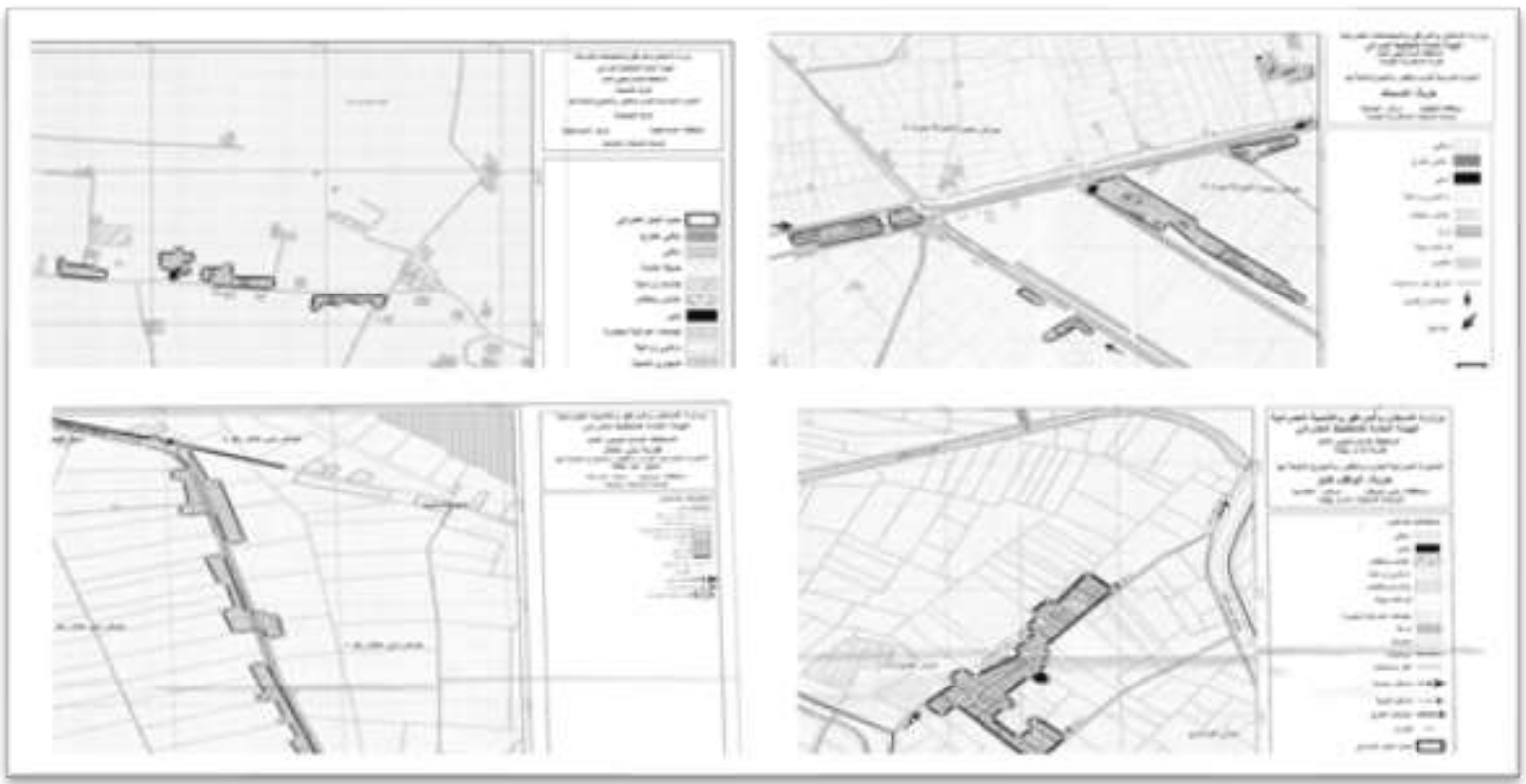

شكل (؛ ) نماذج توابع شريطية الشكل

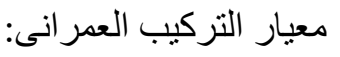

ويتضمن r انماط رئيسية هى: نوابع عبارة عن كتلة واحدة ـ نوابع عبارة عن اكثر من كتلة منصلة ـ نو ابع عبارة عن اكثر شكل (•) نماذج توابع أكثر من كتلة منفصلة

من كتلة منفصلة
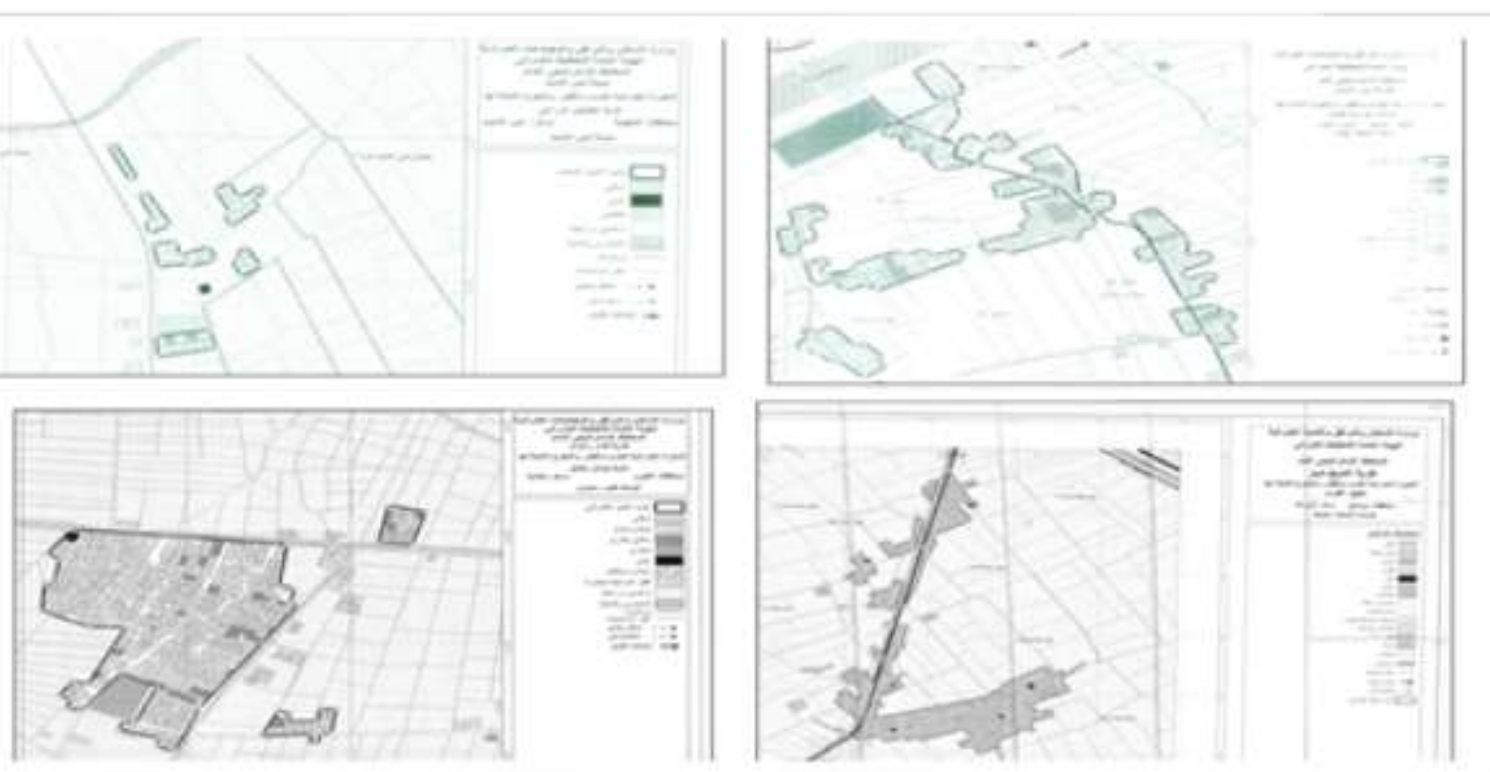

النتائج:

ـ تلعب تو ابع القرى المصرية دورا هاما فى عمر ان الريف المصرى خاصة بالمحافظات الريفية بنطاق وادى النيل و الدلتا

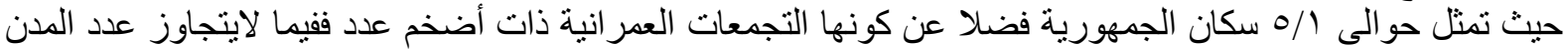

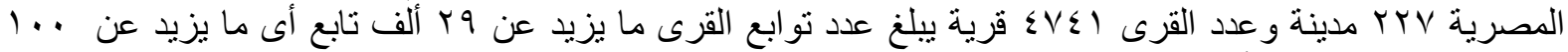

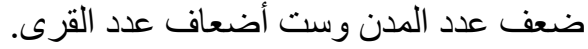

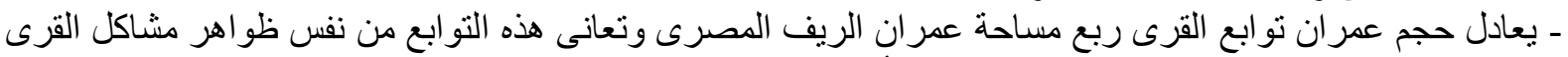

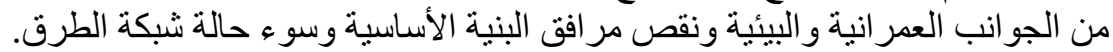

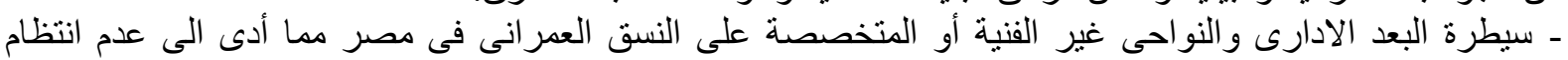

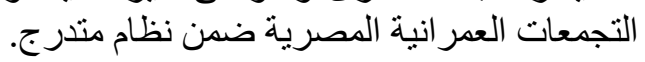


- وجود سيطرة التعامل مع الريف المصرى على أنه القرى فقط دون الالتفات إلى توابعها رغم كبر عددها بل وزيادة

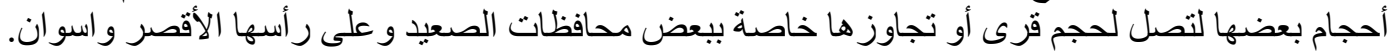

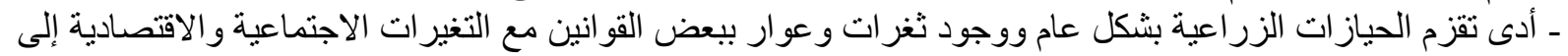

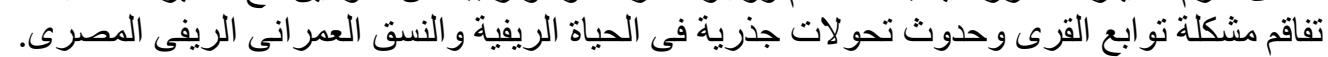

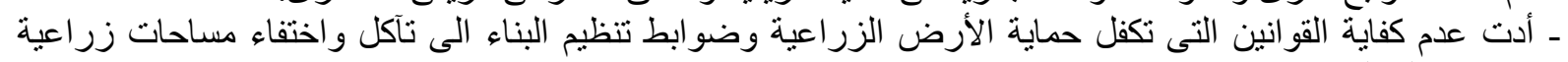

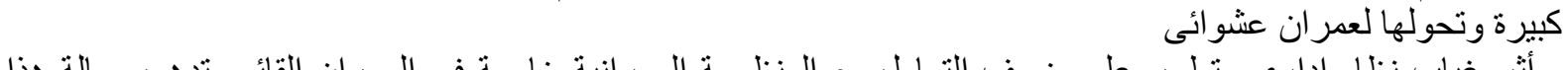

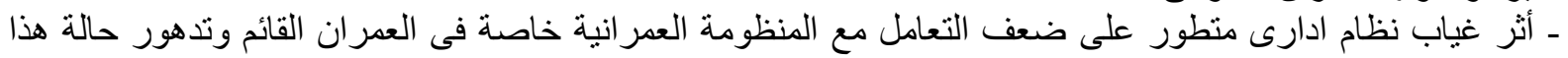

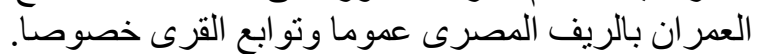

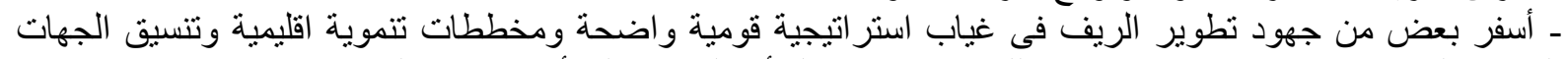
المعنية بالتطوير مع بعضها عن محاو لات للتحسين غير فاعلة أو ملموسة ولم تأت بنتائجها المرجوة. ـ ضرورة تحقيق التوازن بين التنمية فى المجتمعات الريفية والحضرية فى اطار متكامل بين المستويات التخطيط القومى

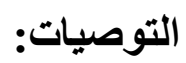

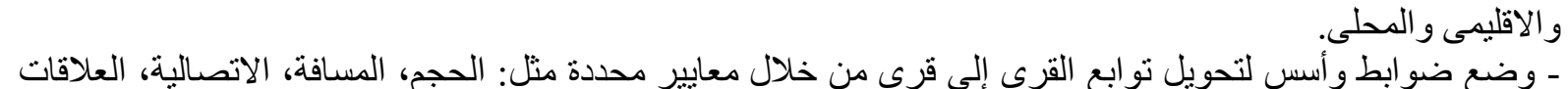

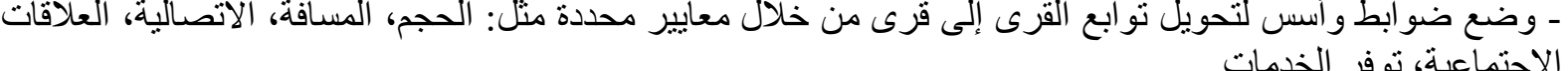
ـ ضرورة توصيل مر افق البنية الأساسية لتوابع القرى وتحسين ونطوير الخدمات بها بما بواكب ظروف وطبيعة هذه التجمعات.

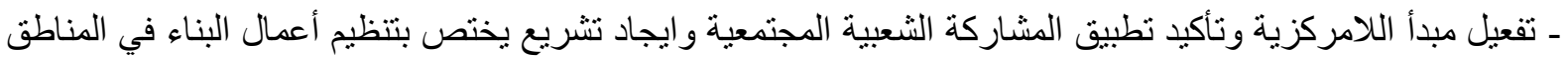

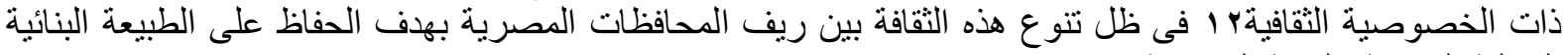
المحلية الخاصة بالقرية المصرية وتونة ابعها.

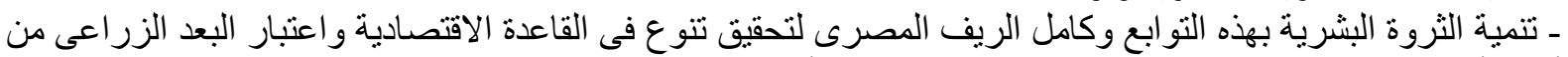

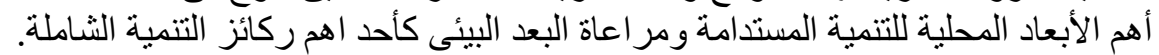

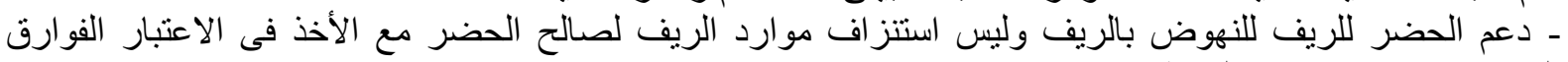

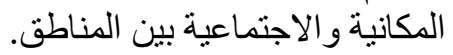

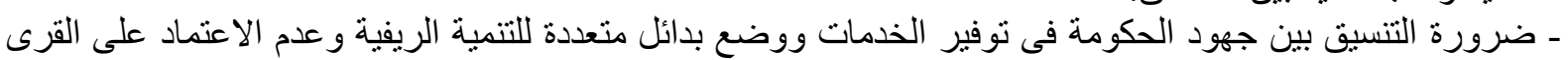

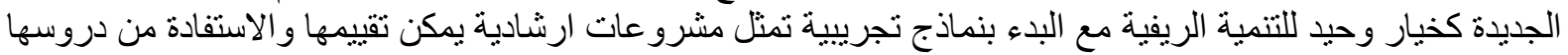
قبل التعميح.

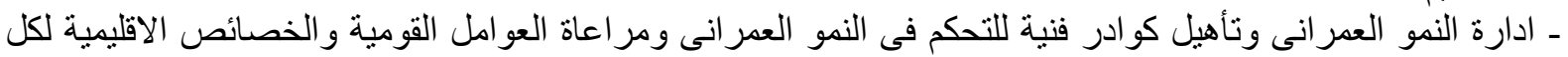

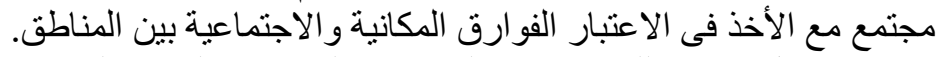

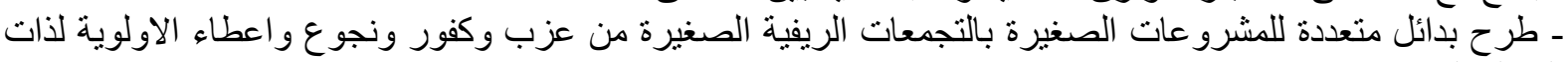
العمالة الكثيفة.

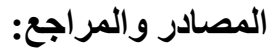

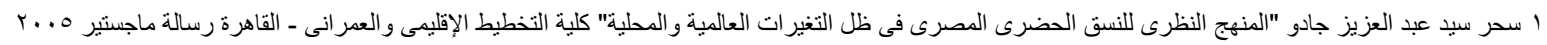

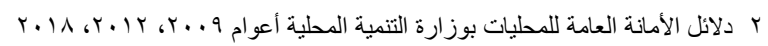

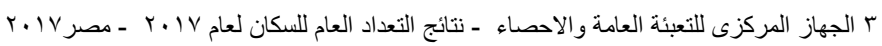

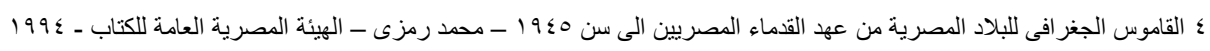

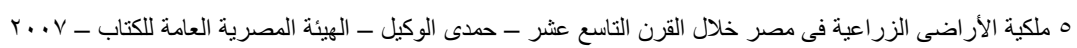

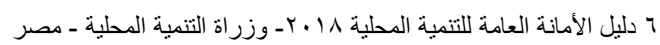

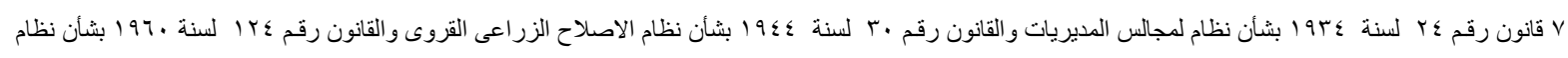
الادارة المحلية

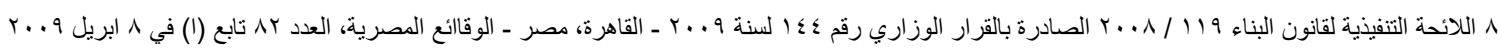

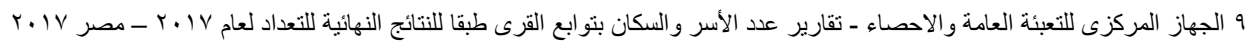

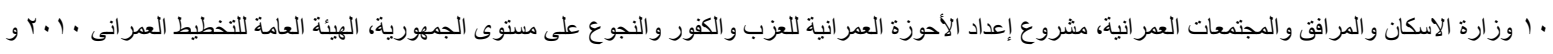

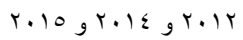

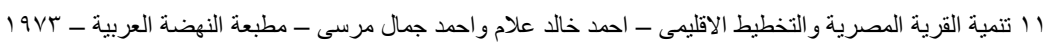

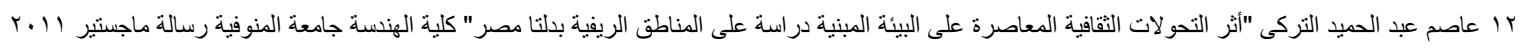

